\title{
TGF- $\beta$ Mediated Cell Adhesion Dynamics and Epithelial to Mesenchymal Transition in 3D and 2D Ovarian Cancer Models
}

\author{
Wafa Al Ameri ${ }^{1,3}$, Ikhlak Ahmed ${ }^{1}$, Fatima M. Al-Dasim ${ }^{1}$, Yasmin Ali Mohamoud ${ }^{2}$, Iman K. Al- \\ Azwani $^{2,3}$, Joel A. Malek ${ }^{1,2}$, Thasni Karedath ${ }^{1}$ \\ ${ }^{1}$ Department of Genetic Medicine, Weill Cornell Medicine-Qatar, Education City, Qatar Foundation, \\ P.O. Box No. 24144, Doha, Qatar \\ ${ }^{2}$ Genomics Core, Weill Cornell Medicine-Qatar, Education City, Qatar Foundation, Doha, Qatar \\ ${ }^{3}$ Sidra Medical Research Center, Doha, Qatar \\ Correspondence to: Thasni Karedath, e-mail: $\underline{\text { tka2001@qatar-med.cornell.edu }}$
}

Phone No: +974 3338-4832

\begin{abstract}
Background: Three-dimensional (3D) tumor cultures in vitro have recently regained attention as they have been acclaimed to have higher similarity to in vivo tumors than cells grown in conventional monolayers (2D). Cancer cells in 2D monolayers fail to mimic the exact tumor microenvironment existing in the real clinical samples. The $3 \mathrm{D}$ anchorageindependent cancer models can better explain the cell adhesion properties in ovarian cancer cells.

Results: Transcriptome profiling of 3D models compared to 2D models in various cancer cell lines shows differential expression of TGF- $\beta$-mediated and cell adhesion pathways. Presence of TGF- $\beta$ in these cell lines shows an increased invasion potential which is specific to cell type. We decided to choose two ovarian cancer cell lines as model systems to study Epithelial to Mesenchymal Transition (EMT) and cancer invasion based on their invasion potential and ability to switch the cadherins expression. TGF- $\beta$ modulation in EMT and cancer invasion was successfully depicted in both 2D and 3D models of SKOV3 and CAOV3 cell lines. Functional evaluations in $3 \mathrm{D}$ and $2 \mathrm{D}$ models demonstrate that the addition of the exogenous TGF- $\beta$ can induce EMT and invasion in cancer cells by turning them into aggressive phenotypes. TGF- $\beta$ receptor kinase I inhibitor (LY364947) can revert TGF- $\beta$ effect in these cells.

Conclusions: In a nutshell, TGF- $\beta$ can induce EMT and migration, increase aggressiveness, increase cell survival, alter cell characteristics, remodel the Extracellular Matrix (ECM) and increase cell metabolism favorable for tumor invasion and metastasis.
\end{abstract}

\section{Key words}

TGF- $\beta$, ovarian cancer, EMT, SKOV3, 3D models 


\section{Background}

Ovarian cancer is one of the most lethal gynecological malignancies accounts for $5 \%$ cancer deaths among women (Bray et al., 2018). The overall survival of ovarian cancer patients is less than $30 \%$, as its diagnosis occurs after the metastatic spread with a very high rate of recurrence and chemoresistance (Bast et al., 2009; Lengyel, 2010). The long term cure for the later stage cancer is challenging as little known about the underlying mechanisms promoting ovarian cancer progression (Agarwal and Kaye, 2003). Most of the cancer studies relay on in vitro tumor models; like established cell lines and mouse xenograft models. Majority of the tumor models fails to explain the aggressive phenotype represents in the real situation. These models usually help to identify the tumorigenicity of cancer cells and the involvement of surrounding microenvironment. But these systems are usually not sufficient to explain the initial metastatic event cascades like tumor invasion and EMT (Kunjithapatham et al., 2015). Studying these events are crucial as it may lead to a better understanding of key metastatic events occurring primarily. Also, it may help to identify important molecular targets that is involved in increasing metastatic potential of some tumor subtypes. Identification of a sensitive molecular target controlling invasion and metastasis events that lead to EMT remains elusive. The lack of proper model system to study EMT and invasion is another limitation in this research area.

The in vitro cancer cell line models of $2 \mathrm{D}$ cultures are not an ideal system to explain the molecular mechanisms controlling EMT, metastasis and chemoresistance. Moreover, 2D models usually lack biological requirements which explain hypoxia and angiogenesis. When cancer cells grown in 2D, they have a uniform and rapid proliferation across the plastic surface unlike the 3D models that show many zones of differential proliferation and cell division; mostly confined to outer zones (Katt et al., 2016; Lin and Chang, 2008). The growing cells in 3D capture more phenotypic heterogeneity due to difference in growth, access of nutrients and oxygen leading to selection pressure and resembling in vivo tumor organoids. Since tumor spheroids have oxygen and nutrient grades, 3D models could be established to test these theories with greater ease than serially passaged $2 \mathrm{D}$ models. The significance of 3D spheroid model systems has been comprehensively reviewed and clearly illustrated that cell-matrix interactions are better recreated by a complex aggregated cell population rather than a simple cell monolayer 2D culture (Bissell and Radisky, 2001; Debnath and Brugge, 2005; Griffith and Swartz, 2006; Loessner et al., 2013). It has been reported that $3 \mathrm{D}$ in vitro model of epithelial ovarian carcinoma (EOC) restores the functional differentiation of the tissue in vivo in a manner that cannot be achieved in the 2D monolayer cultures (Debnath and Brugge, 2005; Griffith and Swartz, 2006; Xu et al., 2011). The organotypic 3D models considerably reduce time and cost of drug discovery too (Nath and Devi, 2016). The current study is focusing on 3D models of ovarian cancer cell lines and their response towards prolonged exposure to the transforming growth factor beta (TGF- $\beta$ ).

It is a well-known phenomenon that TGF- $\beta$ plays an important role in the tumor progression and actin cytoskeleton reorganization (Nguyen et al., 2009). The role of TGF- $\beta$ in inducing 
cell proliferation, invasion and migration in 3D culture is rarely studied in ovarian cancer. The present study evaluates the role of TGF- $\beta$ in cell growth, invasion and metastasis and whether it may induce a complete EMT in both $2 \mathrm{D}$ and $3 \mathrm{D}$ cultures irrespective of the proliferation rate. The more invasive phenotypes developed by continuous TGF- $\beta$ treatment and its role in cell adhesion are as well deciphered in the current study. The inhibitory effect of the selective inhibitor of TGF- $\beta$ RI (LY364947) in ovarian cancer cells has been analyzed. The present study evaluates the role of LY364947 in controlling cell proliferation and invasion of cancer cells.

\section{Results}

\section{TGF- $\beta$ is a potent inducer of cancer cell invasion in selected ovarian cancer cell lines}

Global gene expression studies by RNA-Seq analysis in anchorage-independent 3D ovarian cancer cells compared to $12 \mathrm{D}$ models have shown that TGF- $\beta$ signaling is one of the most altered pathways in 3D spheroid models (Figure 1 A) (Supplementary File 2, Supplementary Figure 2). 3D spheroids can efficiently upregulate the genes involved in cell migration; Hypoxia Inducible Factor1A (HIF1A) and integrin signaling (Figure $1 \mathrm{~A}, \mathrm{~B}$ ). qRT-PCR analysis -to identify genes involved in ECM remodeling- suggests the same pattern of gene expression in 3D spheroids compared to 2D models. qRT-PCR analysis confirms an efficient rearrangement of cell adhesion genes in 3D spheroids compared to 2D models (Table 1). 3D spheroids overexpress a distinct group of genes in various levels which can induce migration and invasion compared to control group in ovarian cancer cells. These experiments established 3D cultures that can induce an invasive EMT phenotype to a limited extent. Next, the majority of the population was transformed to EMT phenotype by adding exogenous TGF- $\beta$ to $3 \mathrm{D}$ spheroids. The prolonged TGF- $\beta$ exposure can enhance the ability of cells to maintain mesenchymal properties for long period of time (Gregory et al., 2011). 3D ovarian cancer models were treated with a prolonged TGF- $\beta$ exposure for 14 days in order to check the proliferation and efficacy of invasion capacity in the rearranged models. 3D spheroid models treated with TGF- $\beta$ have been used as model systems to study EMT and invasion.

Invasion of 3D spheroids was measured by matrigel coated Boyden Chamber Assay (Figure 1 c). These cells that have undergone EMT induction by adding TGF- $\beta$ and its control were used for in vitro invasion assay. Briefly, cells that migrated through matrigel and 8-micron pore size membrane towards 5\% serum were then counted (Bauer et al., 2005). Cells undergone EMT have exhibited much higher rate migration or invasion than the control. Most of the ovarian cancer cell lines with epithelial phenotype shows significant increase in the invasion potential of TGF- $\beta$-induced EMT condition compared to the control cells. There is a significant increase in cancer cell invasion in APOCC, SKOV3, and CAOV3 cell lines (Figure $1 \mathrm{c}$ ). Highly aggressive teratocarcinoma cell line PA-1 and drug resistant cell line A2780 fail to show any significant difference in invasion potential compared to the other cell lines. The invasion percentage increase in all ovarian cancer cells due to TGF- $\beta$ induction suggests that TGF- $\beta$ is a potential inducer of migration and invasion in ovarian cancer.

\section{TGF- $\beta$ can induce invasiveness and trigger partial EMT in the 3D spheroids}

Seven cell lines (SKOV3, PA-1, CAOV3, A2780, A2780 CIS, APOCC, OVCAR3) were used to analyze expression pattern of the EMT signature genes in the presence of TGF- $\beta 1$. 
The 3D spheroids treated with TGF- $\beta$ for 14 days partially activate EMT by inducing some of the EMT signature genes (Figure $1 \mathrm{D}$ ).

From the Figure 1D, it is clear that CAOV3 is one of the most potential candidates to study cancer invasion in ovarian cancer cells. CAOV3 and SKOV3 cells significantly upregulate EMT markers; like fibronectin 1 (FN1), N-cadherin (CDH2), Vimentin (VIM) and downregulate E-cadherin (CDH1) compared to the other cell lines (Figure 1 D). The significant reduction in E-cadherin in CAOV3 and SKOV3 cells treated with TGF- $\beta$ indicates its ability to switch cadherins and induce EMT which is essential for cancer invasion. Only CAOV3 and SKOV3 cells respond to TGF- $\beta$ treatment and activate EMT partially by upregulating some EMT signature genes; like matrix metalloproteinase (MMP2), FN1 and VIM and downregulating E-cadherin. Each cell line responded to the TGF- $\beta$ treatment in a very unique way. Invasive cancer cells exhibit a minimal alteration in EMT gene expression while epithelial-like cancer cell lines -especially CAOV3- show a higher level of expression and mesenchymal phenotype. The above results suggest that CAOV3 and SKOV3 cell lines can be potent model systems to study EMT and invasiveness in ovarian cancer cells.

\section{Anchorage-independent models of ovarian cancer cell lines form distinct type of multicellular spheroids}

We established anchorage-independent models for five cancer cell lines by culturing them in ultra-low attachment plate for 14 days. Cell lines display different sizes of 3D structures in anchorage-independent cultures (Figure 2 A). PA-1 and SW626 cell lines form compact and large spheroids in anchorage-independent cultures. The spheroids formed in anchorageindependent cultures of SKOV3, OVCAR3 and CAOV3 are very loosely shaped. These cells exhibit the ability to spread and invade through the thick collagen matrix (Figure 2 A). PA-1, SKOV3, CAOV3 cells show a better invasion and migration in the collagen matrix by spreading thoroughly in the thick matrix.

A2780, APOCC, CAOV3, A2780 CIS cell lines show a significant increase in the spheroid size in TGF- $\beta$-treated multiple cell spheroids. In contrast, SKOV3 cell line displays a significant reduction in the size of the spheroids when treated with TGF- $\beta$. Among the 3D model systems, CAOV3 and A2780 cell lines increase the spheroid size significantly compared to the other cell types (Figure 2 B). The spheroids size of PA-1 and SW626 remains unaltered even after 14 days of TGF- $\beta$ treatment. Obviously, TGF- $\beta$ treatment increases the spheroid size and facilitates the spreading of the spheroids in the collagen matrix efficiently. PA-1 and SKOV3 cell lines show a mesenchymal phenotype in the collagen-embedded matrix treated with TGF- $\beta$. SKOV3 and PA-1 form star-like appearance of multicellular aggregates containing cells with spindle-like morphology which are associated with invasive phenotypes (Bidarra et al., 2016; Kenny et al., 2007).

The size of the TGF- $\beta$-treated and control spheroids was also analyzed. The average size of the spheroids of the ovarian cancer cell lines is as following: PA-1 [433 um], SKOV3 [339um], OVCAR3 [55um], SW626 [149um], APOCC [50um], A2780 [53um], A2780 CIS [44um], CAOV3 [26um] (Figure $2 \mathrm{~B}$ ). Most of the cell lines displays an increased spheroid size in the presence of TGF- $\beta$ while SKOV3 cell line shows a smaller but more compact spheroids after treating with TGF- $\beta$. CAOV3 and A2780 cell lines have the least spheroidogenesis capacity among the cell lines that have been studied, but they were able to form spheroids of large size and better compactness after the TGF- $\beta$ treatment. In conclusion, 
TGF- $\beta$ treatment can increase the size and compactness of spheroids in most of the ovarian cancer cell lines studied.

\section{Cell lines display different affinity towards ECM components}

Our next aim was to study whether TGF- $\beta$ treatment could alter affinity towards various important ECM components. Not all ovarian cancer cells exhibit similar pattern of adhesion affinity towards ECM components alone or in combination. SKOV3 cells show the highest affinity towards ECM components as shown in the intensity plot (Figure $3 \mathrm{~A}$ ). SKOV3 is the only cell line that displays a better attachment ability on ECM matrix in comparison to the other cell lines. We selected SKOV3 cell line to analyze the effect of TGF- $\beta$ in altering cell adhesion affinity towards various combinations of ECM components. TGF- $\beta$ facilitates adhesion of cells in different ECM components (Figure $3 \mathrm{~B}$ ). The intensity plot of cell adhesion pattern in SKOV3 cells treated with TGF- $\beta$ demonstrates that TGF- $\beta$ does not only facilitate adhesion towards most of the $36 \mathrm{ECM}$ combinations, but also facilitates migration by increasing the adhesion capacity on the promigratory ECM components; like fibronectin and laminin (Figure $3 \mathrm{~B}$ ). The representative raw data image of SKOV3 cells in ECM array (Supplementary Figure 1) shows that cells display a better attachment in almost all combinations treated with TGF- $\beta$ with a high affinity towards fibronectin and combinations of fibronectin with other ECM compounds. TGF- $\beta$ R1 selective inhibitor LY364947 facilitates a reversion of ECM affinity in TGF- $\beta$-treated cells.

\section{TGF- $\beta$ treatment induces significant cell growth only in 3D models of CAOV3 cell line}

TGF- $\beta$ increases cell growth percentage in CAOV3, APOCC and A2780 cis cell lines in 2D models compared to the other cell lines (Figure 4 A). Only CAOV3 cell line shows a significant cell growth increase in both $2 \mathrm{D}$ and $3 \mathrm{D}$ models. Anchorage-independent model of CAOV3 shows an increase in cell growth under the influence of TGF- $\beta$ (37\%). The CAOV3 cells change its epithelial phenotype to an elongated mesenchymal phenotype after treatment with TGF- $\beta$ (Figure 4 B). Although TGF- $\beta$ increases invasion potential and cell adhesion pattern in different cell lines, it fails to induce cell proliferation in all cell lines except in 3D CAOV3 model. CAOV3 is the only reported cell line to have an increased growth potential as a response to the prolonged TGF- $\beta$ treatment.

\section{TGF- $\beta$ receptor kinase I inhibitor (LY364947) delays wound healing and decreases invasion ability in CAOV3 cell line}

CAOV3 and SKOV3 are the promising cell lines to study invasion and migration among the selected cancer cells both in $2 \mathrm{D}$ and $3 \mathrm{D}$ in vitro models. In order to validate the effect of TGF- $\beta$ in these cancer cells, we used conventional 2D cultures for TGF- $\beta$ inhibitor-based study. Both cell lines responded well with the TGF- $\beta$ treatment and increased the invasive and migratory potential. TGF- $\beta$ treatment fastened the wound healing process and facilitated invasion (Figure $4 \mathrm{C}, \mathrm{D}$ ). In contrast, the TGF- $\beta$ inhibitor treatment reverted the effect of TGF- $\beta$ (Figure 4 C, D). Our study confirms that CAOV3 and SKOV3 cell lines respond well to the exogenous TGF- $\beta$ and its effect can be reverted or minimized by the addition of TGF- $\beta$ specific inhibitor. The results suggest that CAOV3 and SKOV3 cells are particularly sensitive to the exogenous TGF- $\beta$ which can induce invasion and migration.

\section{LY364947 decreases cell proliferation and ATP production in a concentration-} dependent manner in $2 \mathrm{D}$ model 
Selective inhibitor of TGF- $\beta$ RI (LY364947) was able to induce cell proliferation reduction in a dose-dependent manner with an IC50 value of $52.73 \mathrm{nM}$ in CAOV3 and $118.5 \mathrm{nM}$ in SKOV3 in 2D models (Figure 5 A, B left panel). The treatment with LY364947 also reduced the ATP production (Figure 5 A, B right panel). Since the compound can induce cell death at a very high concentration, we decided to use a lower concentration of $10 \mathrm{uM}$ for further study. The OCR, basal respiration and OCR-linked ATP production are higher in SKOV3 cells treated with TGF- $\beta$ compared to control and TGF- $\beta$ inhibitor-treated cells (Figure 5 C). The TGF- $\beta$ specific inhibitor clearly reduces cell proliferation and ATP production, inhibits wound healing and decreases OCR level suggesting that TGF- $\beta$ inhibitor reverses TGF- $\beta$ effect in SKOV3 and CAOV3 cells.

In conclusion, we demonstrated that both $2 \mathrm{D}$ and $3 \mathrm{D}$ phenotypes are efficient models in cancer invasion and migration studies. TGF- $\beta$-a well known cytokine for its protumorigenic properties in cancer- can induce partial EMT in SKOV3 and CAOV3 cells both in 2D and 3D models. Our results suggest that TGF- $\beta$ can induce partial EMT, cell survival, increased metabolism, ECM remodeling and sensitivity to LY364947 (Figure 6). Furthermore, our results highlight the importance of TGF- $\beta$ in tumor invasion in SKOV3 and CAOV3 cells and it can be proposed as a model system to study cancer cell migration and invasion.

\section{Discussion}

Results of the current study revealed that 3D anchorage-independent spheroids turned out to be an aggressive phenotype as it activates most of the EMT inducing genes and downregulates E-cadherin in the cell lines that were studied. CAOV3 and SKOV3 3D models retain a better phenotype by upregulating most of the cell adhesion molecules; like collagen 1, 3 and 5 (Table 1). As reported earlier, all the cell lines show a typical EMT signaling called cadherin switching. E-cadherin shows a downregulation and $\mathrm{N}$-cadherin upregulates in cells that undoes EMT (Hazan et al., 2000; Islam et al., 1996). E-cadherin shows a downregulation and $\mathrm{N}$-cadherin shows a remarkable upregulation in all the $3 \mathrm{D}$ spheroid models. EPCAM -a cell adhesion signature molecule that can help in inducing metastasis by abrogating the E-cadherin activity- is also upregulated in these models. EPCAM abrogates Ecadherin activity by reducing cell-to-cell adhesion (Winter 2003). EPCAM upregulation in all the 3D spheroids shows invasive potential. Only CAOV3 cell line shows a remarkable upregulation of the SNAIL and TWIST transcription factors among all the cell lines that have been experimented (24-fold and 10.5-fold respectively). Classical cadherins are the transmembrane component of the adherens junction. Cadherins mediate cell-cell adhesion through their extracellular domains and connect to the actin cytoskeleton by associating with catenin through their cytosolic domain. E-cadherin is usually associated with epithelial cells. Absence of E-cadherin and activation of N-cadherin have been shown to promote motility mesenchymal characteristics and cell invasion (Hazan et al., 2000; Islam et al., 1996).

3D models show an abnormal ECM that may promote invasion. An increase in collagen deposition or ECM stiffness alone or in combination upregulate integrin signaling and promotes survival and proliferation (Schedin and Keely, 2011; Wozniak et al., 2003). Studies show that cancer cells migrate rapidly in areas rich with collagen fibers (Wang et al., 2003). Collagen type IV has potent stimulatory action on angiogenesis. Dense fibrillar collagen is a potent inducer of invadopodia via specific signaling network (Artym et al., 2015). Collagen shows a remarkable upregulation in all the cancer cell lines under study. Collagens; like COL1, COL3, COL4, COL15 and COL 6, show a relative increase in the expression of 3D 
spheroids. It has been reported that COLI, II, V, IX have an increased deposition during tumor formation (Huijbers et al., 2010; Zhu et al., 1995). Increased collagen deposition can increase matrix stiffness and thereby increase ECM stiffness and eventually induce adhesion and migration (Huijbers et al., 2010). In general, collagen remodels the ECM and facilitates invasion. The 3D spheroid can be a good model to study collagen remodeling in cancer. Among the cell lines, SKOV3 shows a distinct pattern in cell adhesion gene expression compared to the other cell lines where it expresses most of the collagen types (Table 1).

RNA-Seq analysis, showing differential expression in 3D and 2D phenotypes, revealed that 3D spheroids show better cell-to-cell interaction and cell adhesion (Supplementary File 2). Surprisingly, it upregulates the TGF- $\beta$ and HIF1 pathways leading a conclusion that metastatic potential of a cell phenotype does not depend on the proliferation rate in $3 \mathrm{D}$ models. Erwin et al., reported that a direct comparison of transcriptional profiling of 3D cultures and xenografts to monolayer cultures yielded upregulation of networks involved in hypoxia, TGF- $\beta$ and Wnt signaling as well as regulation of EMT in colorectal cancers (Boghaert et al., 2017). A recent study shows that reversal of anchorage-independent 3D spheroid into a monolayer 2D model gives a totally different phenotype from the original 2D and mimics a metastatic model (Kunjithapatham et al., 2015). Our results likewise suggest that 3D spheroids have more heterogeneity and activate tumor-promoting pathways compared to $2 \mathrm{D}$ models. The most noted one among those pathways is TGF- $\beta$ pathway for EMT. EMT is thought to be activated in cancer cells, linked to their dissociation from the primary tumor and intravasation into blood vessels (Thiery et al., 2009). However, the impact of the EMT in cancer progression and patient survival is still far from fully understood, from skepticism (Lee et al., 2006; Morikawa et al., 1988; Tarin et al., 2005) to fundamental support (Lamouille et al., 2014; Ye et al., 2015). Some observations in mouse models suggest notes of caution on the true role of EMT in cancer progression (Fischer et al., 2015; Zheng et al., 2015). Recently Weinberg and his team experimentally verified the contribution of EMT in metastasis with direct genetic evidence of the critical role EMT processes in breast and pancreatic tumor metastasis, challenging the Fisher et al. observations about EMT (Aiello et al., 2017; Fischer et al., 2015; Ye et al., 2017). The cells in the 3D structures are expressing more EMT related genes compared to $2 \mathrm{D}$ structures. A recent study in $3 \mathrm{D}$ in vitro model of mammary epithelial cells shows transition between epithelial and mesenchymal states during EMT induction by TGF- $\beta$ and its reversion by withdrawing TGF- $\beta$ in culture (Bidarra et al., 2016). We investigated the role of the exogenous TGF- $\beta$ in enhancing EMT in 3D cancer spheroids in an anchorage-independent condition.

TGF- $\beta$ is a pleiotropic cytokine that controls proliferation, differentiation, embryonic development, angiogenesis, wound healing and other functions in many cell types. TGF- $\beta$ acts as a tumor suppressor in normal epithelial cells and in early stage of tumor progression. In advanced cancers, the corrupted TGF- $\beta$ pathway induces many activities that lead to growth, invasion and metastasis of cancer cells (Derynck et al., 2014; Massagué, 2008; Moustakas and Heldin, 2012). TGF- $\beta$ also induces tissue fibrosis through induction of various extracellular matrix proteins. Recently, numerous studies have revealed that TGF- $\beta$ stimulates EMT in certain epithelial cells (Moustakas and Heldin, 2012). TGF- $\beta$ induces progression of cancer through EMT which is an important step in the invasion and metastasis of cancer (Xu et al., 2009).

In our study, TGF- $\beta$ seems to induce a partial EMT -like most tumor cells- in the cell lines studied in 3D spheroids. Our results suggest that TGF- $\beta$ can induce partial EMT and enhance invasion potential in ovarian cancer cells. As per earlier studies depending on signaling 
context, epithelial cells that lose some epithelial characteristics or attain both epithelial and mesenchymal characteristics are called partial EMT (Lamouille et al., 2014). The proteins of the MMP family are involved in the breakdown of ECM, promote degradation of ECM and cleave cell adhesion molecules such as cadherin, thus potentiating cell motility (Cirri and Chiarugi, 2011). The real-time analysis shows an upregulation of MMPs which means that most of the cell lines we experimented induce EMT except CAOV3 and SKOV3. CAOV3 is the only cell line showing an increase in the cell proliferation rate calculated using MTS assay. It has been described that TGF- $\beta 1$ is not only responsible for EMT induction, but also capable to arrest mammary epithelial cell cycle (Tan et al., 2015). For cells to acquire mesenchymal-like phenotype, growth arrest is necessary in most cases (Tran et al., 2011). Even though cells show less growth potential in the presence of TGF- $\beta$, they increase the invasion ability of cells in a significant manner in all the ovarian cancer cell lines that we studied. Matrigel invasion assay shows that cells are capable of migrating efficiently in the presence of TGF- $\beta$ compared to control. None of the cell lines exhibit significant cytotoxicity over LY94647 at a very low concentration. Only CAOV3 and SKOV3 cells show cell growth reduction at a higher concentration of the inhibitor. Wound healing and matrigel invasion assays in CAOV 3 cells exhibit more invasion arrest and less migration after treatment with TGF- $\beta 1$ in a lower concentration. Collagen embedded invasive assay shows that TGF- $\beta$ treatment can enhance invasion in all the cell lines irrespective of its growth potential. TGF- $\beta$ treatment significantly increases the spheroid diameter in most of the cell lines studied.

We used ECM array to investigate the interaction between TGF- $\beta$ induction in cancer cells and ECM stimuli. ECM array has 36 combinations of ECM protein conditions that are deposited onto the hydrogel surface as printed array spots. Among the cell lines studied, SKOV3 shows a better adhesion capacity and responds well with TGF- $\beta$ treatment. SKOV3 cells show a better and stronger attachment to many of the ECM combinations compared to the other cell lines. The intensity plot shows that SKOV3 has a better attachment compared to the other cell lines. EMT in the SKOV3 cell line is ECM component-dependent. Fibronectin and laminin combination show more attachment in SKOV3 cells after TGF- $\beta$ induction. Combinations of ECM show a better attachment ability compared to individual ECM component. Reversion of SKOV3 cells attachment to ECM components caused by LY364947 treatment indicates that TGF- $\beta$ can induce ECM specific remodeling. TGF- $\beta$ treatment shows increased OCR, ATP-linked OCR and basal respiration in SKOV3 cells and these effects were reverted back while LY364947 treatment (Figure 5 C). Taken together treatment with TGF- $\beta$ can induce EMT, ECM remodeling, increase metabolism, cell survival in SKOV3 and CAOV3 cells (Figure 6).

Among the cell lines studied, CAOV3 and SKOV3 are the two promising cell lines to be used as a model system for studying EMT and invasiveness in ovarian cancer cells. Both $3 \mathrm{D}$ and $2 \mathrm{D}$ models of SKOV3 and CAOV3 cells responding to TGF- $\beta$ and its receptor specific inhibitor treatments signifies that both cell lines are promising to study EMT or invasion in cancer. Prolonged TGF- $\beta$ induction in 3D models are more promising, as it can mimic the whole tumor microenvironment and explain many cell adhesion properties. As TGF- $\beta$ inhibitors are mainly targeting the tumor microenvironments with a minimal cytotoxicity, they should be used in combination with cytotoxic agents to kill the cancer cells and revert tumor favorable microenvironments. LY364947 has a potential to be a future TGF- $\beta$-targeted anti-cancer therapy, since it efficiently reverses the effect of TGF- $\beta$ in cancer cells.

\section{Materials and Methods}




\section{Cell lines and treatment}

Eight ovarian cancer cell lines -PA-1, SKOV3, SW626, CAOV3, OVCAR3 (cells were obtained from American Type Cell Collection, Manassas, VA), APOCC (cell line derived from ascites fluid), A2780, and A2780 CIS (A2780 cisplatin-resistant cell line) (Sigma, St. Louis, MO)- have been used for the current study. Cells were cultured in DMEM (Life technologies, NY. USA) supplemented with $10 \%$ fetal bovine serum (FBS) (Life technologies, USA). Cell cultures were incubated at $37^{\circ} \mathrm{C}$ in a humidified atmosphere, $5 \%$ $\mathrm{CO}_{2}$-injected incubator. Cell confluency and morphology were routine checked. Cells were washed with phosphate-buffered saline (PBS) (Life technologies, USA) then fresh growth media $-10 \%$ FBS DMEM- was added every two to three days. Cellular viability was determined by Trypan blue exclusion in TC20 Automated Cell Counter (Bio-Rad, USA).

\section{Anchorage-independent growth of multicellular ovarian cancer spheroids spheroids)}

(3D

Multicellular cancer spheroids (MCS) were generated from a heterogeneous parental population by seeding cells growing during log-phase in $100 \mathrm{~mm}$ ultra-low attachment culture dishes (Corning Inc. PA, USA), culturing them in DMEM /F12 supplemented with 5\% FBS then incubated at $37^{\circ} \mathrm{C} 5 \% \mathrm{CO}_{2}$ incubator. Cells were grown in ultra-low attachment dishes for 2 weeks to make 3D anchorage-independent models. The 3D anchorage-independent models were imaged by Axio Imager 2 Research Microscope (Zeiss, Jena, Germany) and the average size of the spheroids was measured using the Zeiss ZEN Microscope Software for Microscopic Components.

\section{Real-time PCR analysis}

The relative expressions of 11 genes involved in cell adhesion and EMT were determined by real-time PCR. Total RNA was isolated from cells using RNeasy Mini Kit (Qiagen, Germany). cDNA synthesis was done using first strand cDNA synthesis kit for RT-PCR (AMV) (Roche Applied Science). FastStart Universal SYBR Green Master (Rox) (Roche Applied Science) was used to amplify the specific gene using cDNA primers obtained from PrimerBank (http://pga.mgh.harvard.edu/primerbank/) (Supplementary File 1). Each realtime assay was done in triplicate and run in StepOnePlus Real-Time PCR System (Applied Biosystems, USA). The internal control gene beta-actin and the target genes were amplified with equal efficiencies. Gene expressions were analyzed using relative quantification (RQ) method. The RQ method estimates the differences in gene expression against a calibrator; control without treatment. The fold change of the targeted gene expression was calculated using a standard formula: $2^{-\Delta \Delta \mathrm{ct}}\left(2^{-\Delta \Delta \mathrm{ct}}=\Delta \mathrm{C}_{\mathrm{T}}\right.$ treated $-\Delta \mathrm{C}_{\mathrm{T}}$ control $)$.

\section{ECM cell adhesion assay}

ECM-cell adhesion pattern of different ovarian cancer cells was analyzed by using MicroMatrix ECM Array (Microstem, San Diego, CA). Array consists of 36 different combinations of selected cell adhesion molecules. Cells were attached to the ECM combinations according to its specificity towards different ECM components. Images were extracted using GE Typhoon Array Scanner after fixing and staining the array with TOPRO®-3 Stain (life technologies). Cell adhesion patterns of TGF- $\beta$-treated and untreated samples were also analyzed by extracting the intensity of cells attached to the ECM using ImageQuant TL 8.1 Software. 


\section{TGF- $\beta$ treatment}

Anchorage-independent spheroids were treated with 10ng/ml TGF- $\beta 1$ (PeproTech, NJ, USA) for 2 weeks. Spheroid size was measured by Axio Imager 2 Research Microscope (Zeiss, Jena, Germany) and average size of the spheroids was measured using the Zeiss ZEN Microscope Software.

\section{Collagen invasion assay}

Two weeks old spheroids (both TGF- $\beta$-treated and control) were seeded on the top of collagen gel (Collagen I RatTail, Life technologies) with a concentration of $2 \mathrm{mg} / \mathrm{ml}$ in chamber slides (BD technologies, CA, USA).

\section{Cell proliferation assay}

The effect of TGF- $\beta$ on cell proliferation in different cell lines was measured by CellTiter 96® ${ }^{\circledR} Q_{\text {ueous }}$ One Solution Cell Proliferation Assay (MTS) (Promega, CA, USA). Cells were grown in 2D (96 well plate BD) and 3D anchorage-independent condition using Corning ultra-low attachment 96 well plate (Sigma-Aldrich) with seeding density of 5000 cells per well for 3 days. The effect of cell proliferation in the presence of TGF- $\beta$ and TGF- $\beta 1$ receptor specific inhibitor LY364947 (Tocris Bioscience, MN, USA) in 2D and 3D models was measured.

\section{Cell migration-scratch wound assay}

The CAOV3 cells were cultured in 6-well plates with seeding density of $1 \times 10^{6}$ cells/well. Confluent cell monolayers were disrupted by standardized wound scratching using a sterile $200-\mu \mathrm{l}$ pipette tip and incubated in serum-free culture medium with $10 \mathrm{ng} / \mathrm{ml}$ TGF- $\beta 1$ in both treated and LY364947 treated cells. Migration of cells into the bare area and recovering of monolayer was evaluated every 12 hours for 72 hours using Axio Imager 2 Research Microscope (Zeiss, Jena, Germany) and average distance of the scratch was measured using Zeiss ZEN Microscope Software.

\section{Cell invasion assay}

The transwell chamber (Corning, New York, USA) was used to measure the invasive abilities of cells according to the modified protocol. Briefly, the pre-treated with or without TGF- $\beta 1$ $(10 \mathrm{ng} / \mathrm{ml})$ cells were seeded $\left(2.5 \times 10^{5}\right.$ cells/well $)$ onto the top chamber of ECM-coated with $8 \mu \mathrm{m}$ pore membrane filter. ECM consists of a combination of matrigel, collagen I and fibronectin $(2: 1: 1)$ or matrigel alone $(10 \mathrm{mg} / \mathrm{ml})$. $2 \mathrm{ml}$ of DMEM supplemented with $10 \%$ FBS was placed in the bottom chamber as a chemoattractant. Invasion was evaluated by counting the number of cells penetrating the membrane; counting the cells in the top chamber (noninvasive) and bottom of the membrane (invasive). Those cells -which have undergone EMT induction either with or without the addition of TGF- $\beta$ - were used for in vitro invasion assay. Cells that migrated through matrigel and 8-micron pore size membrane towards the medium with 5\% serum are then counted (Bauer et al., 2005). The percentage of invasion was calculated by the formula [number of cells invaded/total number of cellsX100]. 


\section{Oxygen consumption rate (OCR) and extracellular acidification rate (ECAR) by seahorse}

The Seahorse XFe96 Analyzer (Agilent, Santa Clara, USA) was used to continuously monitor OCR and ECAR. 72 hours prior to the experiment, 10000 cells/well were seeded in a XF96 Cell Culture Microplate in DMEM media supplemented with $2.5 \%$ FBS, $25 \mathrm{mM}$ glucose, $2 \mathrm{mM}$ glutamine and cultivated at $37{ }^{\circ} \mathrm{C}$ in humidified atmosphere and $5 \% \mathrm{CO}_{2} .24$ hours after seeding, the cells were treated with TGF- $\beta$ or its inhibitor with the desired concentrations. 24 hours prior to the experiment, $200 \mathrm{ml}$ of XF calibrator was added to each well of the XF cartridge and incubated overnight at $37{ }^{\circ} \mathrm{C}$ in humidified atmosphere and $0 \%$ $\mathrm{CO}_{2} .30$ minutes prior to the experiment, cells were washed with PBS and $200 \mu \mathrm{l}$ of respective XF assay medium was added per well and incubated for 45 minutes at $37{ }^{\circ} \mathrm{C}$ in humidified atmosphere and $0 \% \mathrm{CO}_{2}$. For the XF Cell Mito Stress Test, XF assay medium was supplemented with $5 \mathrm{mM}$ glucose and $2 \mathrm{mM}$ glutamine. After 15 minutes equilibration time, OCR was accessed every 10 minutes -after 3 minutes mix, 3 minutes wait, 3 minutes measure- repeated 3 times after the addition of the respective compounds. The OCR was measured by XFe96 Extracellular Flux Analyzer (Agilent Technologies) with sequential injection of $1 \mathrm{mM}$ oligomycin A, $1 \mathrm{mM}$ FCCP and $0.5 \mathrm{mM}$ rotenone/antimycin A.

\section{Statistical analysis}

Data represent means \pm S.E.M. with at least two to three biological replicas in triplicate. Statistical analyses were determined by using Student's $t$-test. $P<0.05$ was considered as significant difference between groups. The half maximal inhibitory concentration $\left(\mathrm{IC}_{50}\right)$ of LY364947 was calculated using non-linear regression method. The analysis was done using Prism Software Version 7. 


\author{
Abbreviations \\ circ RNA: Circular RNA \\ FDR: False discovery rate \\ RNAseq: RNA sequencing \\ siRNA: Small interspersed RNA \\ qRT-PCR: Quantitative Real Time PCR \\ 3D culture: Three-Dimensional cell culture \\ OCR: Oxygen Consumption Ratio \\ OXPHOS: Oxidative Phosphorylation \\ Declarations
}

\title{
Ethics approval and consent to participate
}

Not applicable for the present study.

All experiments were conducted in cancer cell lines, no human or animal subject is involved in the study.

\section{Consent for publication}

All authors give consent for the publication of the manuscript in Molecular Cancer. 


\section{Availability of data and materials}

The datasets supporting the conclusions of this article are included within this article and the Supplementary Data.

\section{Competing interests}

The authors declare that they have no competing interests.

\section{Funding}

This study was supported by Weill Cornell Medicine and Qatar Foundation (BMRP 1 Malek Pilot FY17).

\section{Authors' contributions}

J-M, and T-K, designed the research; T-K, W-AA, F-AD, S performed cellular experiments. I-AA and Y-AM performed RNA Seq and I-A and J-M performed bioinformatic analysis; A$\mathrm{R}$ provided the cell lines and helped with experimental design; T-K wrote the manuscript. All authors read and approved the final manuscript.

\section{Acknowledgements}

The work was supported by grants from Basic Medical Research Program (BMRP) grant from Qatar Foundation to WCM-Q. We thank Dr Arash Rafii for providing APOCC cancer cells. 
bioRxiv preprint doi: https://doi.org/10.1101/465617; this version posted November 8, 2018. The copyright holder for this preprint (which was not certified by peer review) is the author/funder. All rights reserved. No reuse allowed without permission. 


\section{References}

Agarwal, R., Kaye, S.B., 2003. Ovarian cancer: strategies for overcoming resistance to chemotherapy. Nat. Rev. Cancer 3, 502-516. https://doi.org/10.1038/nrc1123

Aiello, N.M., Brabletz, T., Kang, Y., Nieto, M.A., Weinberg, R.A., Stanger, B.Z., 2017. Upholding a role for EMT in pancreatic cancer metastasis. Nature 547, E7-E8. https://doi.org/10.1038/nature22963

Artym, V. V, Swatkoski, S., Matsumoto, K., Campbell, C.B., Petrie, R.J., Dimitriadis, E.K., Li, X., Mueller, S.C., Bugge, T.H., Gucek, M., Yamada, K.M., 2015. Dense fibrillar collagen is a potent inducer of invadopodia via a specific signaling network. J. Cell Biol. 208, 331-50. https://doi.org/10.1083/jcb.201405099

Bast, R.C., Hennessy, B., Mills, G.B., 2009. The biology of ovarian cancer: new opportunities for translation. Nat. Rev. Cancer 9, 415-428. https://doi.org/10.1038/nrc2644

Bauer, T.W., Fan, F., Liu, W., Johnson, M., Parikh, N.U., Parry, G.C., Callahan, J., Mazar, A.P., Gallick, G.E., Ellis, L.M., 2005. Insulinlike growth factor-I-mediated migration and invasion of human colon carcinoma cells requires activation of c-Met and urokinase plasminogen activator receptor. Ann. Surg. 241, 748-56; discussion 756-8. https://doi.org/10.1097/01.SLA.0000160699.59061.92

Bidarra, S.J., Oliveira, P., Rocha, S., Saraiva, D.P., Oliveira, C., Barrias, C.C., 2016. A 3D in vitro model to explore the inter-conversion between epithelial and mesenchymal states during EMT and its reversion. Sci. Rep. 6, 27072. https://doi.org/10.1038/srep27072

Bissell, M.J., Radisky, D., 2001. Putting tumours in context. Nat. Rev. Cancer 1, 46-54. https://doi.org/10.1038/35094059

Boghaert, E.R., Lu, X., Hessler, P.E., McGonigal, T.P., Oleksijew, A., Mitten, M.J., FosterDuke, K., Hickson, J.A., Santo, V.E., Brito, C., Uziel, T., Vaidya, K.S., 2017. The Volume of Three-Dimensional Cultures of Cancer Cells In Vitro Influences Transcriptional Profile Differences and Similarities with Monolayer Cultures and Xenografted Tumors. Neoplasia 19, 695-706. https://doi.org/10.1016/J.NEO.2017.06.004

Bray, F., Ferlay, J., Soerjomataram, I., Siegel, R.L., Torre, L.A., Jemal, A., 2018. Global cancer statistics 2018: GLOBOCAN estimates of incidence and mortality worldwide for 36 cancers in 185 countries. CA. Cancer J. Clin. https://doi.org/10.3322/caac.21492

Cirri, P., Chiarugi, P., 2011. Cancer associated fibroblasts: the dark side of the coin. Am. J. Cancer Res. 1, 482-97.

Debnath, J., Brugge, J.S., 2005. Modelling glandular epithelial cancers in three-dimensional cultures. Nat. Rev. Cancer 5, 675-688. https://doi.org/10.1038/nrc1695

Derynck, R., Muthusamy, B.P., Saeteurn, K.Y., 2014. Signaling pathway cooperation in TGF- $\beta$-induced epithelial-mesenchymal transition. Curr. Opin. Cell Biol. 31, 56-66. https://doi.org/10.1016/j.ceb.2014.09.001

Estimated numbers of new cancer cases for 2017, excluding basal cell and squamous cell skin cancers and in situ carcinomas except urinary bladder, n.d.

Fischer, K.R., Durrans, A., Lee, S., Sheng, J., Li, F., Wong, S.T.C., Choi, H., El Rayes, T., Ryu, S., Troeger, J., Schwabe, R.F., Vahdat, L.T., Altorki, N.K., Mittal, V., Gao, D., 2015. Epithelial-to-mesenchymal transition is not required for lung metastasis but contributes to chemoresistance. Nature 527, 472-476. https://doi.org/10.1038/nature15748

Gregory, P.A., Bracken, C.P., Smith, E., Bert, A.G., Wright, J.A., Roslan, S., Morris, M., Wyatt, L., Farshid, G., Lim, Y.-Y., Lindeman, G.J., Shannon, M.F., Drew, P.A., KhewGoodall, Y., Goodall, G.J., 2011. An autocrine TGF-beta/ZEB/miR-200 signaling 
network regulates establishment and maintenance of epithelial-mesenchymal transition. Mol. Biol. Cell 22, 1686-98. https://doi.org/10.1091/mbc.E11-02-0103

Griffith, L.G., Swartz, M.A., 2006. Capturing complex 3D tissue physiology in vitro. Nat. Rev. Mol. Cell Biol. 7, 211-224. https://doi.org/10.1038/nrm1858

Hazan, R.B., Phillips, G.R., Qiao, R.F., Norton, L., Aaronson, S.A., 2000. Exogenous expression of $\mathrm{N}$-cadherin in breast cancer cells induces cell migration, invasion, and metastasis. J. Cell Biol. 148, 779-90.

Huijbers, I.J., Iravani, M., Popov, S., Robertson, D., Al-Sarraj, S., Jones, C., Isacke, C.M., 2010. A Role for Fibrillar Collagen Deposition and the Collagen Internalization Receptor Endo180 in Glioma Invasion. PLoS One 5, e9808. https://doi.org/10.1371/journal.pone.0009808

Islam, S., Carey, T.E., Wolf, G.T., Wheelock, M.J., Johnson, K.R., 1996. Expression of Ncadherin by human squamous carcinoma cells induces a scattered fibroblastic phenotype with disrupted cell-cell adhesion. J. Cell Biol. 135, 1643-54.

Katt, M.E., Placone, A.L., Wong, A.D., Xu, Z.S., Searson, P.C., 2016. In Vitro Tumor Models: Advantages, Disadvantages, Variables, and Selecting the Right Platform. Front. Bioeng. Biotechnol. 4, 12. https://doi.org/10.3389/fbioe.2016.00012

Kenny, P.A., Lee, G.Y., Myers, C.A., Neve, R.M., Semeiks, J.R., Spellman, P.T., Lorenz, K., Lee, E.H., Barcellos-Hoff, M.H., Petersen, O.W., Gray, J.W., Bissell, M.J., 2007. The morphologies of breast cancer cell lines in three-dimensional assays correlate with their profiles of gene expression. Mol. Oncol. 1, 84-96. https://doi.org/10.1016/j.molonc.2007.02.004

Kunjithapatham, R., Karthikeyan, S., Geschwind, J.-F., Kieserman, E., Lin, M., Fu, D.-X., Ganapathy-Kanniappan, S., 2015. Reversal of Anchorage-Independent Multicellular Spheroid into a Monolayer Mimics a Metastatic Model. Sci. Rep. 4, 6816. https://doi.org/10.1038/srep06816

Lamouille, S., Xu, J., Derynck, R., 2014. Molecular mechanisms of epithelial-mesenchymal transition. Nat. Rev. Mol. Cell Biol. 15, 178-196. https://doi.org/10.1038/nrm3758

Lee, J.M., Dedhar, S., Kalluri, R., Thompson, E.W., 2006. The epithelial-mesenchymal transition: new insights in signaling, development, and disease. J. Cell Biol. 172, $973-$ 81. https://doi.org/10.1083/jcb.200601018

Lengyel, E., 2010. Ovarian cancer development and metastasis. Am. J. Pathol. 177, 1053-64. https://doi.org/10.2353/ajpath.2010.100105

Lin, R.-Z., Chang, H.-Y., 2008. Recent advances in three-dimensional multicellular spheroid culture for biomedical research. Biotechnol. J. 3, 1172-1184. https://doi.org/10.1002/biot.200700228

Loessner, D., Little, J.P., Pettet, G.J., Hutmacher, D.W., 2013. A multiscale road map of cancer spheroids--incorporating experimental and mathematical modelling to understand cancer progression. J. Cell Sci. 126, 2761-71. https://doi.org/10.1242/jcs.123836

Massagué, J., 2008. TGFbeta in Cancer. Cell 134, 215-30. https://doi.org/10.1016/j.cell.2008.07.001

Morikawa, K., Walker, S.M., Nakajima, M., Pathak, S., Jessup, J.M., Fidler, I.J., 1988. Influence of organ environment on the growth, selection, and metastasis of human colon carcinoma cells in nude mice. Cancer Res. 48, 6863-71. https://doi.org/10.1158/00085472.can-05-0699

Moustakas, A., Heldin, C.-H., 2012. Induction of epithelial-mesenchymal transition by transforming growth factor $\beta$. Semin. Cancer Biol. 22, 446-454. https://doi.org/10.1016/j.semcancer.2012.04.002

Nath, S., Devi, G.R., 2016. Three-dimensional culture systems in cancer research: Focus on tumor spheroid model. Pharmacol. Ther. 163, 94-108. 
https://doi.org/10.1016/j.pharmthera.2016.03.013

Nguyen, D.X., Bos, P.D., Massagué, J., 2009. Metastasis: from dissemination to organspecific colonization. Nat. Rev. Cancer 9, 274-284. https://doi.org/10.1038/nrc2622

Schedin, P., Keely, P.J., 2011. Mammary gland ECM remodeling, stiffness, and mechanosignaling in normal development and tumor progression. Cold Spring Harb. Perspect. Biol. 3, a003228. https://doi.org/10.1101/cshperspect.a003228

Tan, E.-J., Olsson, A.-K., Moustakas, A., 2015. Reprogramming during epithelial to mesenchymal transition under the control of TGF $\beta$. Cell Adh. Migr. 9, 233-46. https://doi.org/10.4161/19336918.2014.983794

Tarin, D., Thompson, E.W., Newgreen, D.F., 2005. The Fallacy of Epithelial Mesenchymal Transition in Neoplasia. Cancer Res. 65, 5996-6001. https://doi.org/10.1158/00085472.CAN-05-0699

Thiery, J.P., Acloque, H., Huang, R.Y.J., Nieto, M.A., 2009. Epithelial-Mesenchymal Transitions in Development and Disease. Cell 139, 871-890. https://doi.org/10.1016/j.cell.2009.11.007

Tran, D.D., Corsa, C.A.S., Biswas, H., Aft, R.L., Longmore, G.D., 2011. Temporal and Spatial Cooperation of Snail1 and Twist1 during Epithelial-Mesenchymal Transition Predicts for Human Breast Cancer Recurrence. Mol. Cancer Res. 9, 1644-1657. https://doi.org/10.1158/1541-7786.MCR-11-0371

Wang, W., Wyckoff, J.B., Wang, Y., Bottinger, E.P., Segall, J.E., Condeelis, J.S., 2003. Gene expression analysis on small numbers of invasive cells collected by chemotaxis from primary mammary tumors of the mouse. BMC Biotechnol. 3, 13. https://doi.org/10.1186/1472-6750-3-13

Winter, A.J., 2003. Expression of Ep-CAM shifts the state of cadherin-mediated adhesions from strong to weak. Exp. Cell Res. 285, 50-58. https://doi.org/10.1016/S00144827(02)00045-9

Wozniak, M.A., Desai, R., Solski, P.A., Der, C.J., Keely, P.J., 2003. ROCK-generated contractility regulates breast epithelial cell differentiation in response to the physical properties of a three-dimensional collagen matrix. J. Cell Biol. 163, 583-595. https://doi.org/10.1083/jcb.200305010

Xu, F., Celli, J., Rizvi, I., Moon, S., Hasan, T., Demirci, U., 2011. A three-dimensional in vitro ovarian cancer coculture model using a high-throughput cell patterning platform. Biotechnol. J. 6, 204-212. https://doi.org/10.1002/biot.201000340

Xu, J., Lamouille, S., Derynck, R., 2009. TGF- $\beta$-induced epithelial to mesenchymal transition. Cell Res. 19, 156-172. https://doi.org/10.1038/cr.2009.5

Ye, X., Brabletz, T., Kang, Y., Longmore, G.D., Nieto, M.A., Stanger, B.Z., Yang, J., Weinberg, R.A., 2017. Upholding a role for EMT in breast cancer metastasis. Nature 547, E1-E3. https://doi.org/10.1038/nature22816

Ye, X., Tam, W.L., Shibue, T., Kaygusuz, Y., Reinhardt, F., Ng Eaton, E., Weinberg, R.A., 2015. Distinct EMT programs control normal mammary stem cells and tumour-initiating cells. Nature 525, 256-260. https://doi.org/10.1038/nature14897

Zheng, X., Carstens, J.L., Kim, J., Scheible, M., Kaye, J., Sugimoto, H., Wu, C.-C., LeBleu, V.S., Kalluri, R., 2015. Epithelial-to-mesenchymal transition is dispensable for metastasis but induces chemoresistance in pancreatic cancer. Nature 527, 525-530. https://doi.org/10.1038/nature16064

Zhu, G.G., Risteli, L., Mäkinen, M., Risteli, J., Kauppila, A., Stenbäck, F., 1995. Immunohistochemical study of type I collagen and type I pN-collagen in benign and malignant ovarian neoplasms. Cancer 75, 1010-7. 


\section{Conflict of interest statement}

The authors have no actual or potential conflict of interest to disclose.

\section{Acknowledgements}

The work was supported by grants from Basic Medical Research Program (BMRP) grant from Qatar Foundation to WCM-Q. We thank Dr. Arash Rafii (Stem cell and Microenvironment lab, WCM-Q) for providing primary ovarian cancer cells APOCC.

\section{Funding Sources}

The research was supported by BMRP fund from Weill Cornell Medicine -Qatar and Qatar Foundation. 


\section{Legends}

Figure 1. A, B: Ingenuity $®$ Pathway Analysis (IPA $®$ ) (QIAGEN Bioinformatics) of genes differentially expressed in 3D SKOV3 model vs. 2D and their associated pathways. C TGF- $\beta$ can increase the invasion potential of the cells in a significant way. APOCC, SKOV3, and CAOV3 show very significant increase in invasion. D Epithelial to mesenchymal signature gene expression pattern in $3 \mathrm{D}$ models treated with TGF- $\beta$ compared to control 3D models. Real-time gene expression analysis shows that 3D models treated with TGF- $\beta$ can activate a partial EMT in most of the ovarian cancer cell lines studied. The data in $\mathbf{C}$ is means with error bars representing Standard Error of Mean (SEM) from three experiments; $* * P<0.01$ (Student's $t$-test).

Figure 2. A: Shows 3D structures of various cell lines. Control and TGF- $\beta$-treated structures show different growth pattern and invasion into the collagen matrigel for most of the cell lines. B shows the size of the 3D spheroids before and after TGF- $\beta$ treatment. The data in $\mathbf{B}$ is means with error bars representing Standard Error of Mean (SEM) from three experiments; $* * P<0.01, * \quad P<0.05$ (Student's $t$-test).

Figure 3: Pattern of cell adhesion on the different molecules depends on the cell type. SKOV3 shows better adhesion (3A) and presence of TGF- $\beta$ increases the cell adhesion on some ECM components more strongly in SKOV3 cells in comparison to control and TGF- $\beta$ specific inhibitor (3B)

Figure 4. A: MTS assay shows the $\%$ increase in growth potential after TGF- $\beta$ treatment. Only CAOV 3 cell lines shows better growth progress compared to other cell lines in the presence of TGF$\beta$. B The image shows the epithelial to Mesenchymal transition of CAOV3 cells after treatment with TGF- $\beta$. The image was taken by using Zeiss inverted microscope using Actin staining. Figure 3C. The effect of TGF- $\beta$ specific inhibitor LY 364947 in cancer cell invasion. Boyden chamber assay shows reduction in invasion potential in CAOV 3 cells treated with TGF- $\beta$ specific inhibitor. D: shows a pictorial representation of in vitro wound healing assay in CAOV 3 cells treated with TGF- $\beta$ specific inhibitor (Ly 364947) and its control. F shows the average distance covered by TGF- $\beta$ specific inhibitor treated CAOV3 cells and its control to heal the wound. The data in $\mathbf{C}$ is means with error bars representing standard error of mean (SEM) from three experiments; $* P<0.05$ (Student's $t$-test).

Figure 5. A, B: left panel Shows \% viability of SKOV3 and CAOV3 cells treated with different concentration of TGF- $\beta$ specific inhibitor LY364947. Right panel shows the relative luminescence of ATP production in SKOV3 cells and CAOV3 cells treated with LY364947. C Represents seahorse assays showing oxygen consumption ratio in the top left panel, basal respiration in the top right panel, ATP production in bottom panel for the SKOV 3 cells treated with TGF- $\beta$ specific inhibitor, TGF- $\beta$ or in combination. The data in $\mathbf{A}, \mathbf{B}, \mathbf{C}, \mathbf{D}$ is means with error bars representing standard error of mean (SEM) from three experiments $* * P<0.01,{ }^{*} P<0.05$ (Student's $t$-test).

Figure 6: Schematic representation of the effect of TGF- $\beta$ treatment in SKOV3 and CAOV3 cells. Figure represents both $2 \mathrm{D}$ and $3 \mathrm{D}$ phenotype of the cancer cells can alter its phenotype in the presence of TGF- $\beta$. 
Figure 1

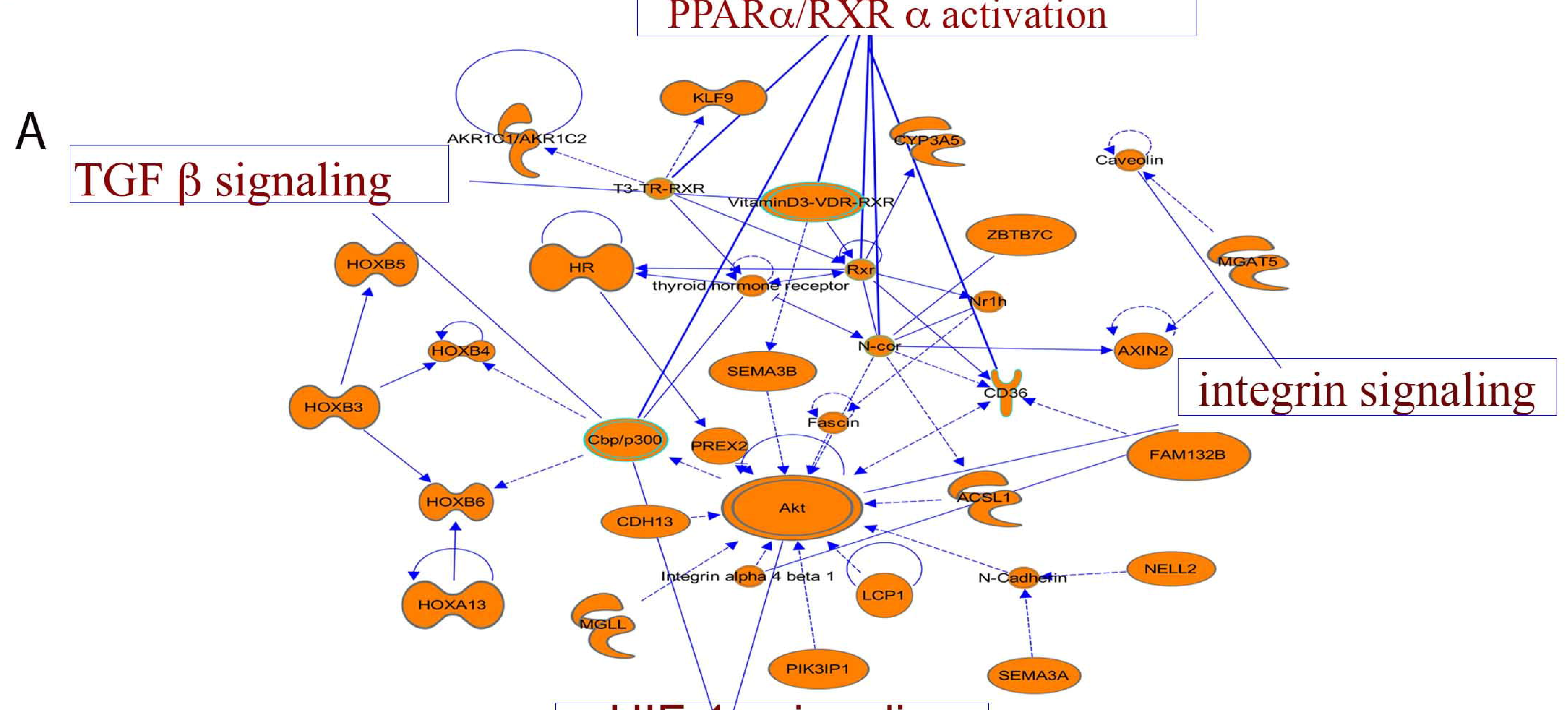

\section{HIF-1a signaling}

B

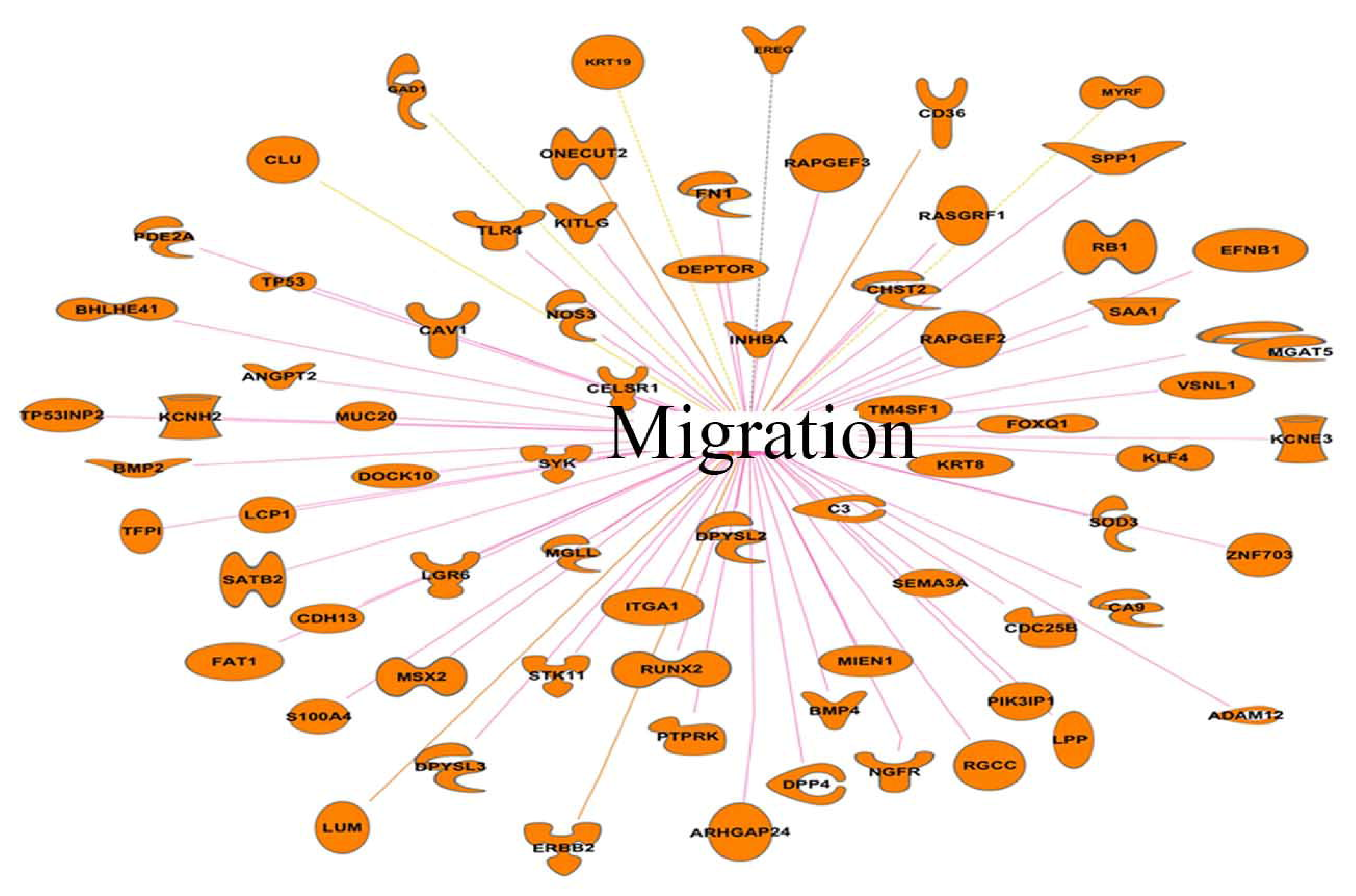

C

$\%$ invasion in control and treated cells

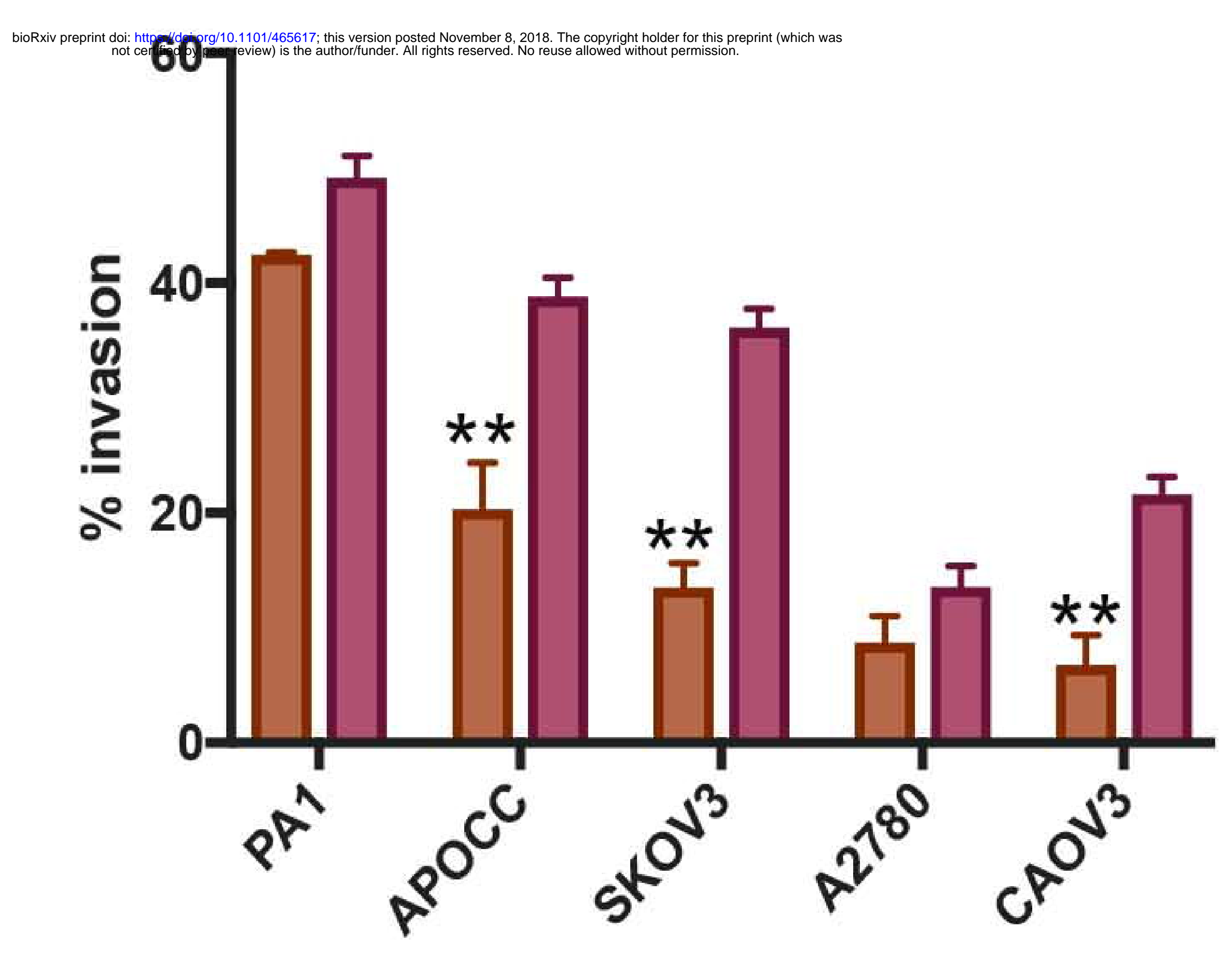

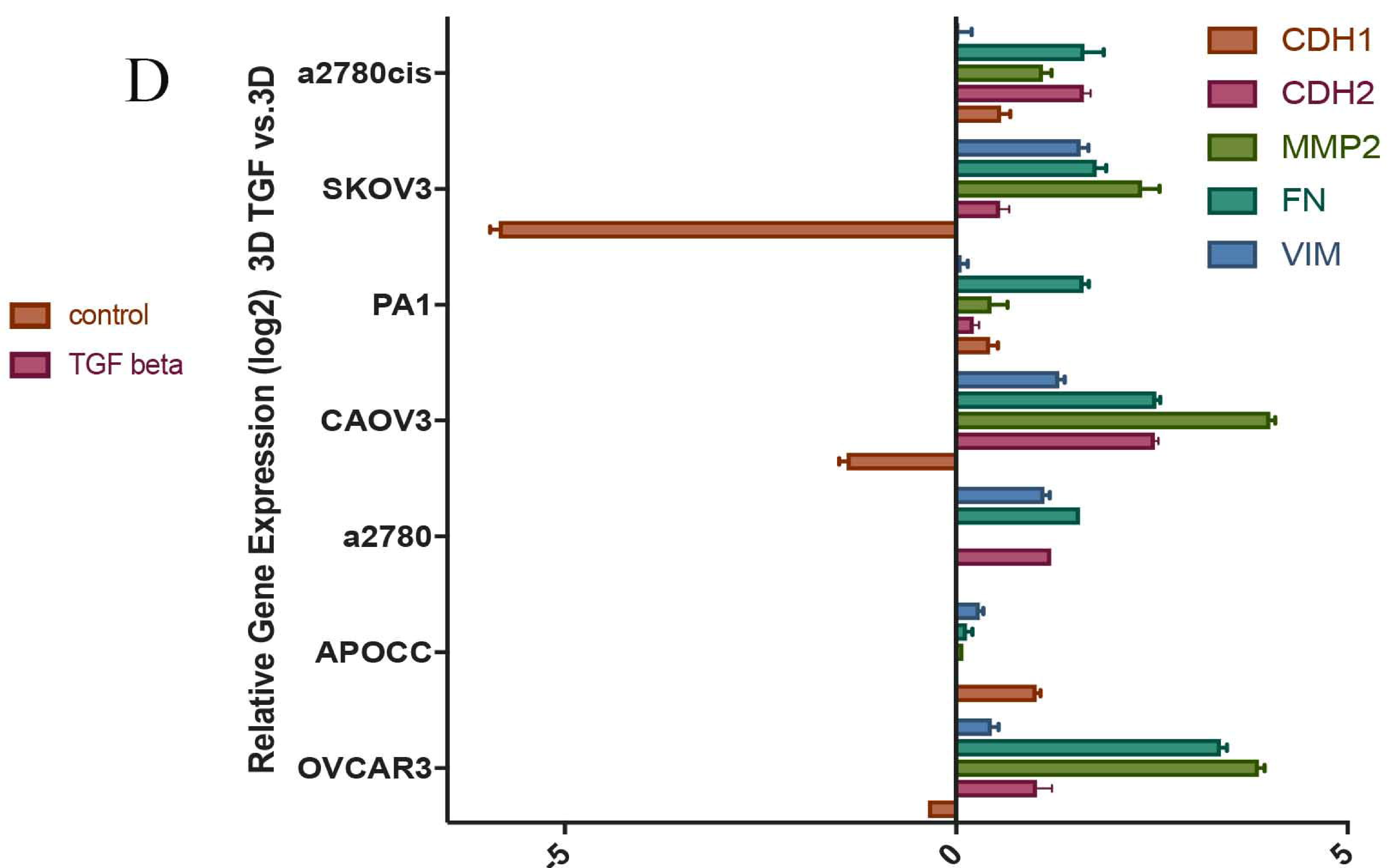


Figure2

A

PA1
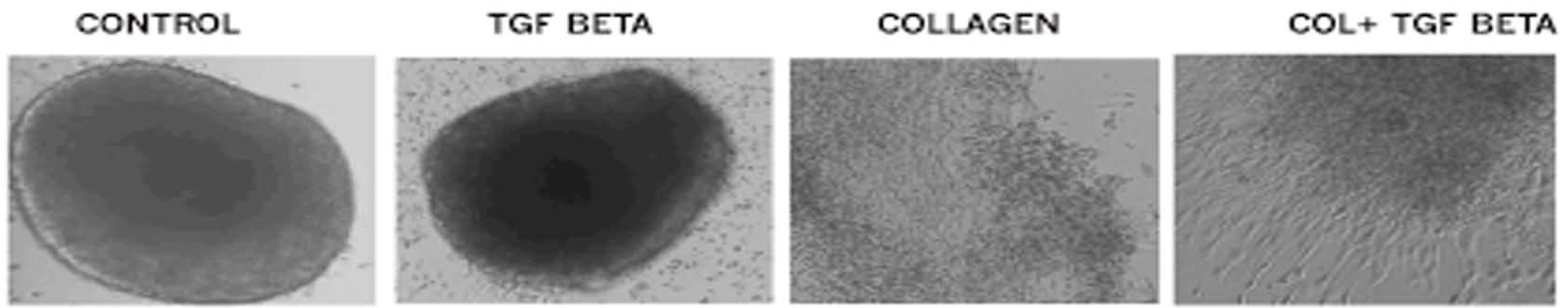

skov3
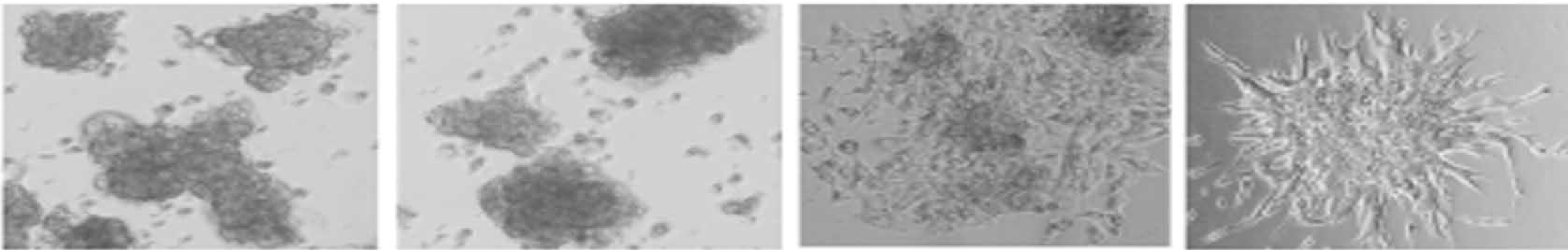

APOCC
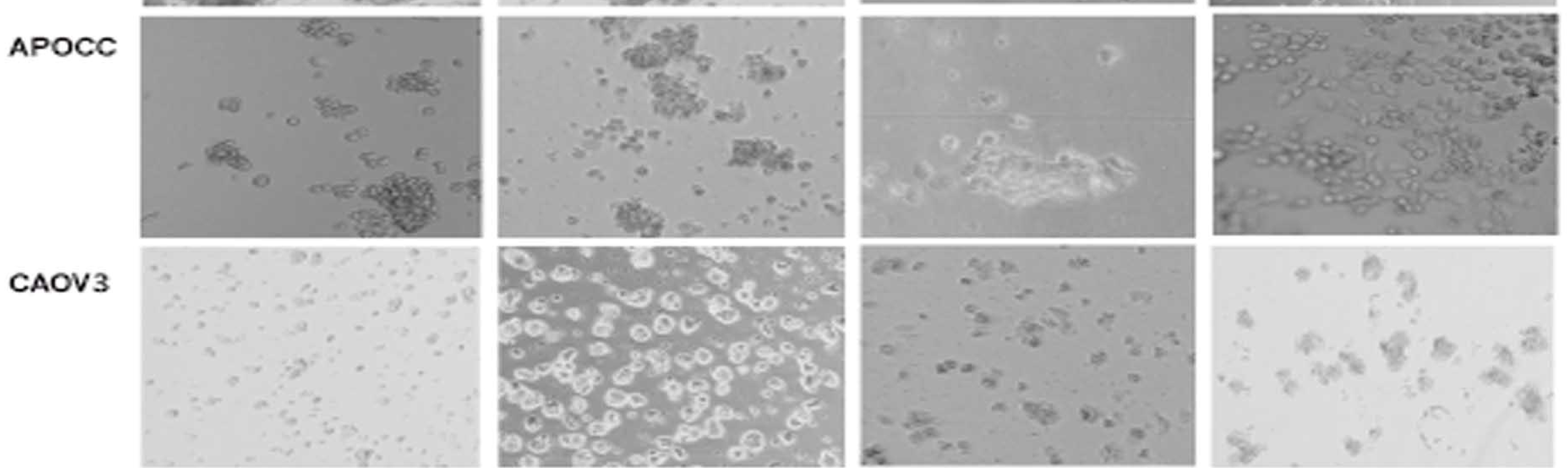

sw626

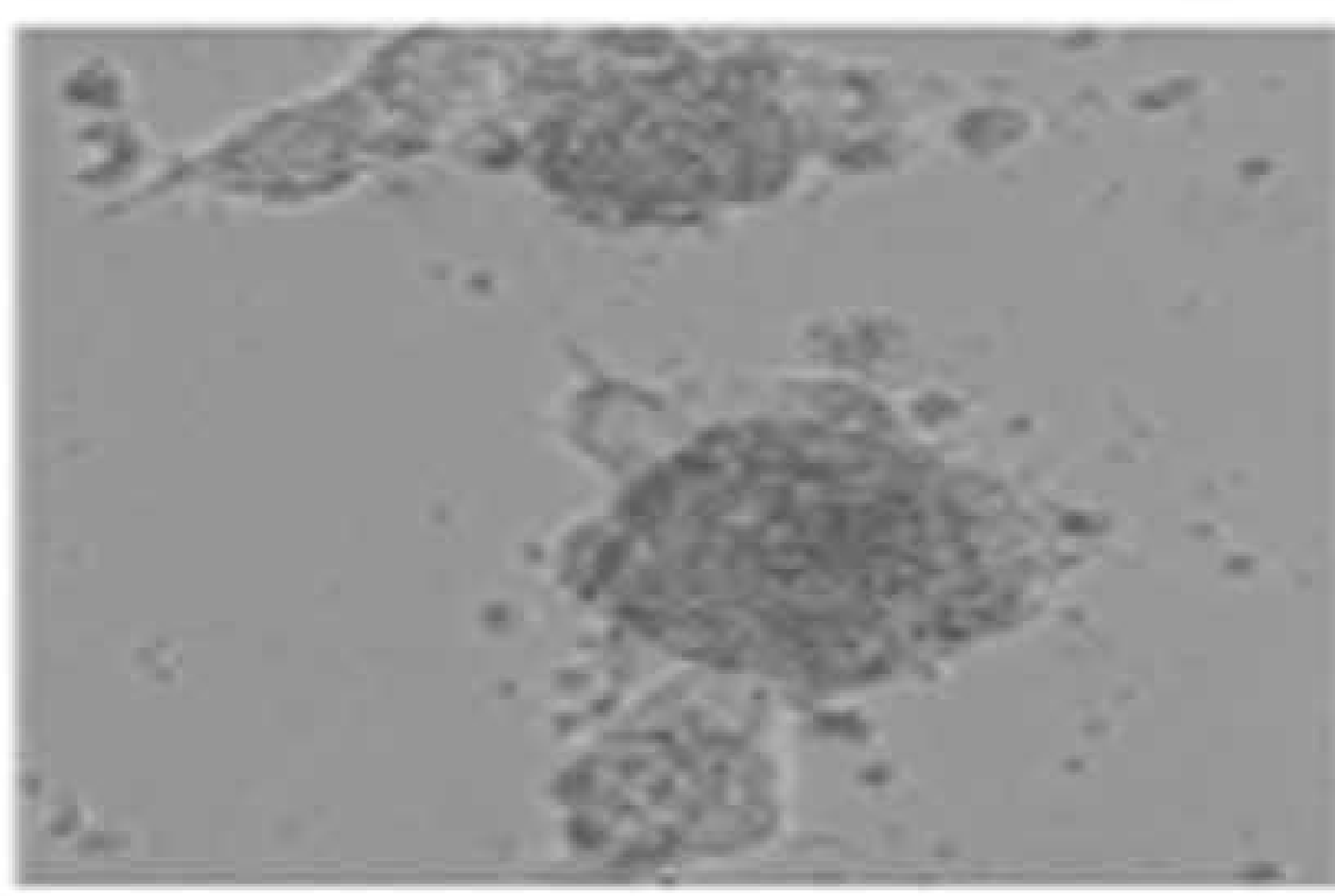

A2780
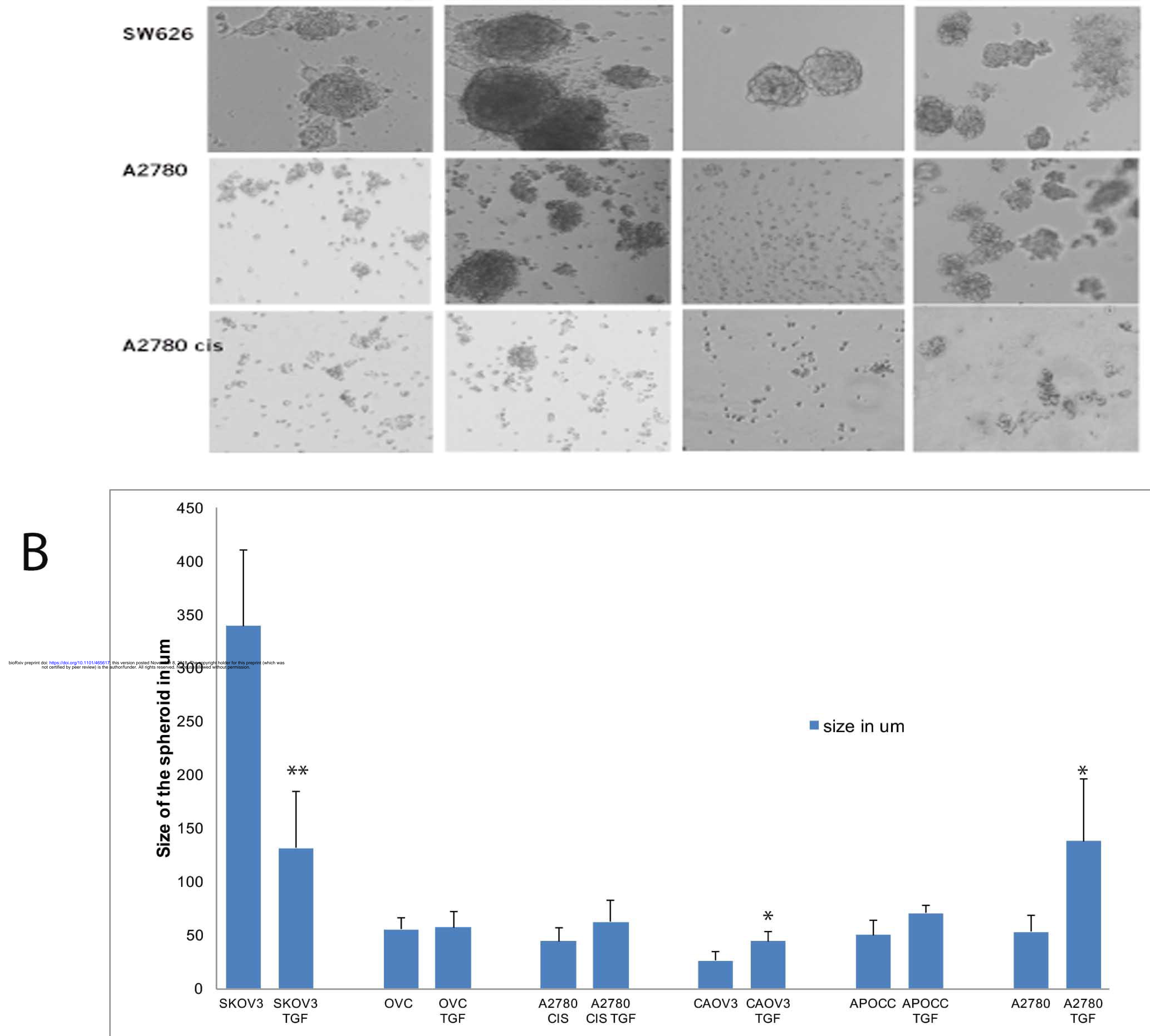

A2780 cis
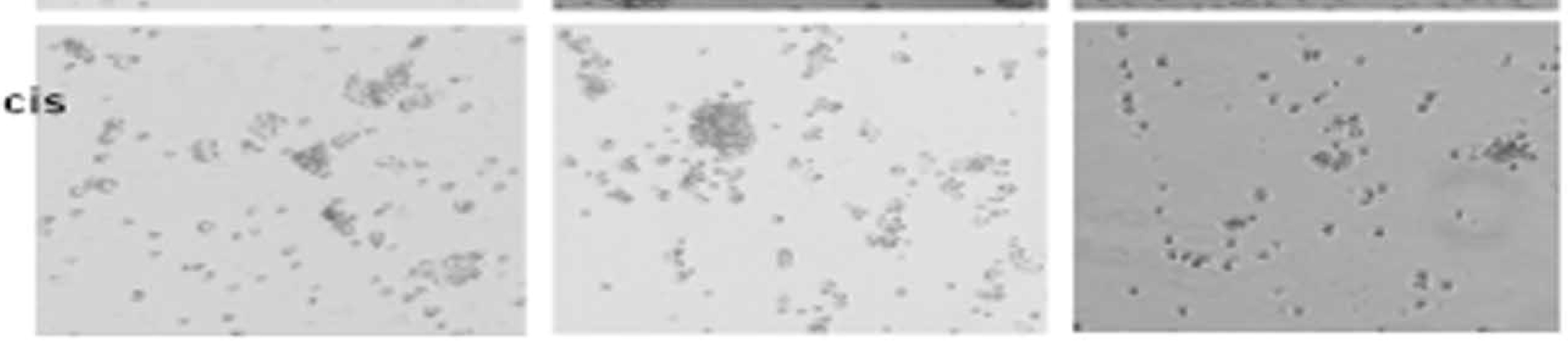
Figure 3

Heatmap showing intensity of cancer cells attachment

A. towads different ECM components

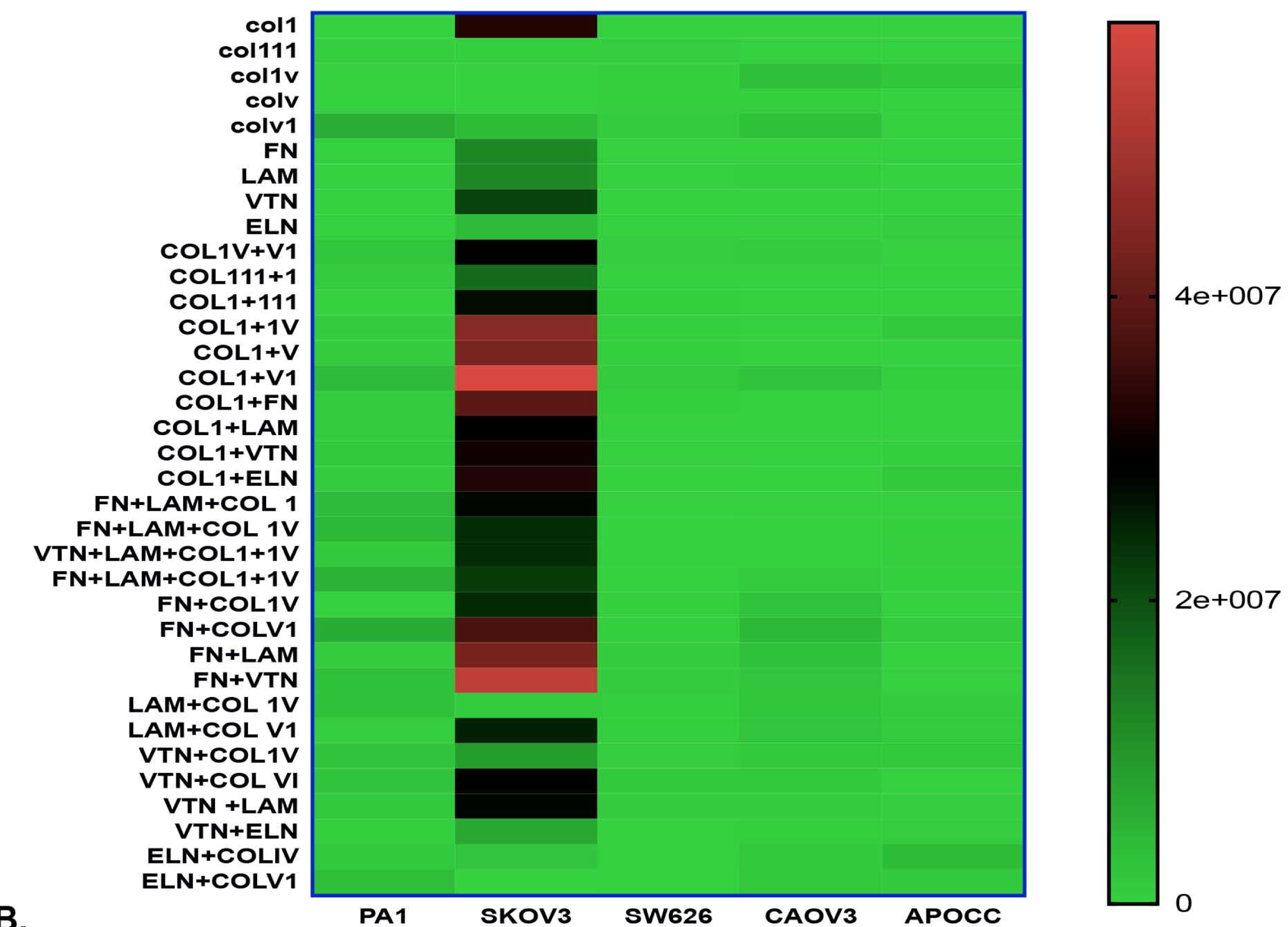

Heatmap showing intensity of SKOV3 cells attachment towards different ECM components after treatment with TGF beta and its inhibitor

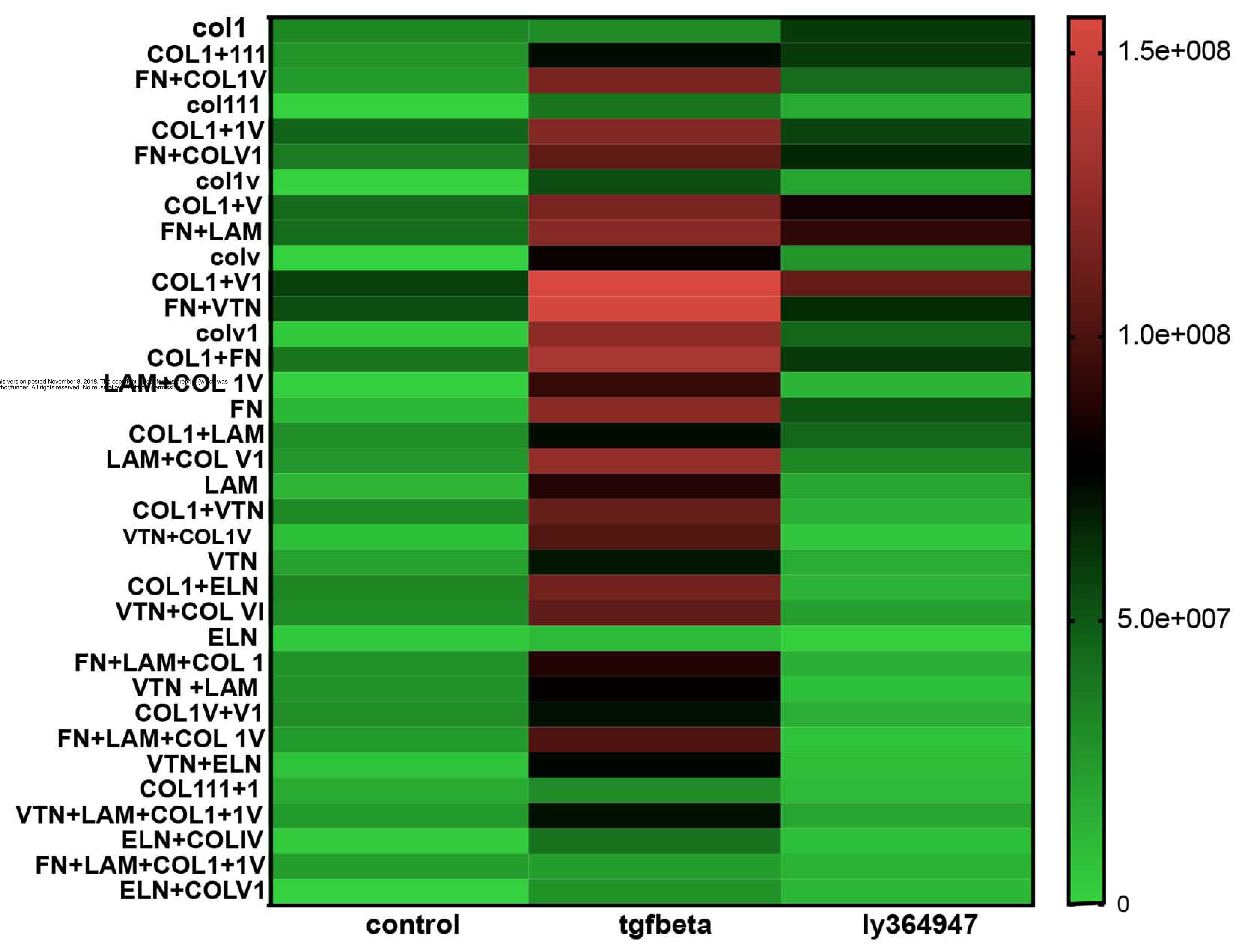


Figure4

A

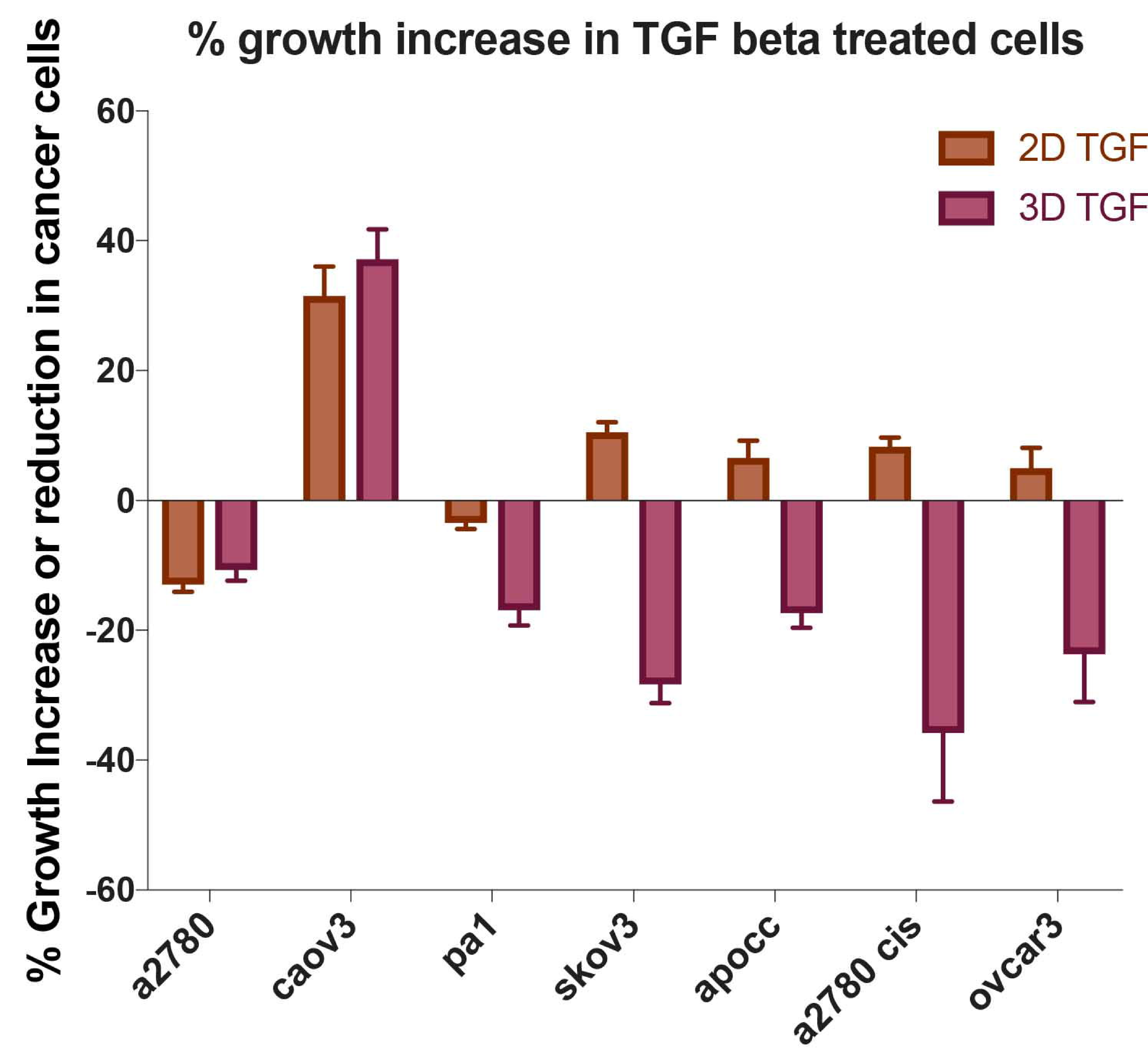

B Caov3 cells treated with TGF beta

C

cell lines

D
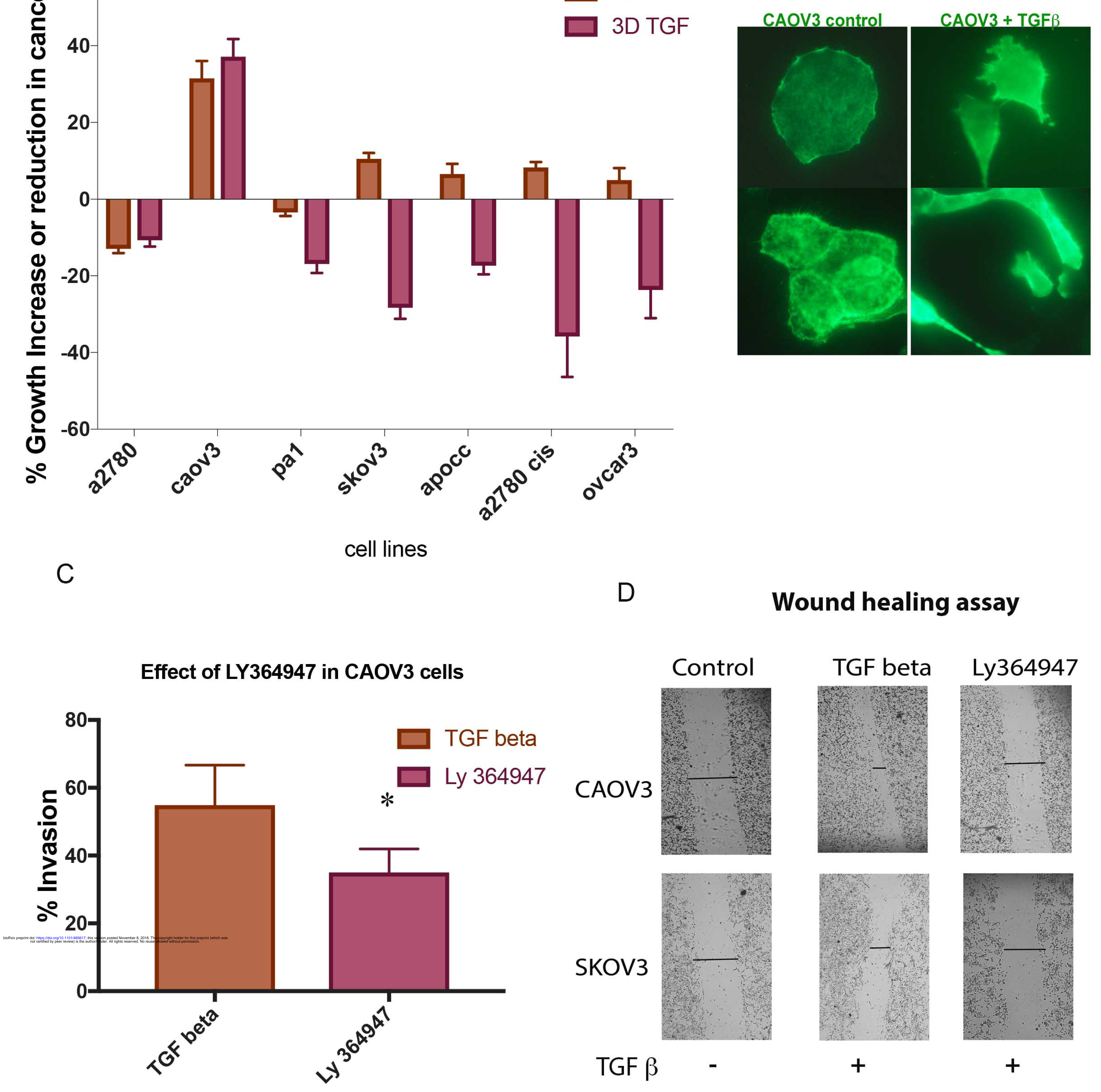

$+$

$+$ 
A

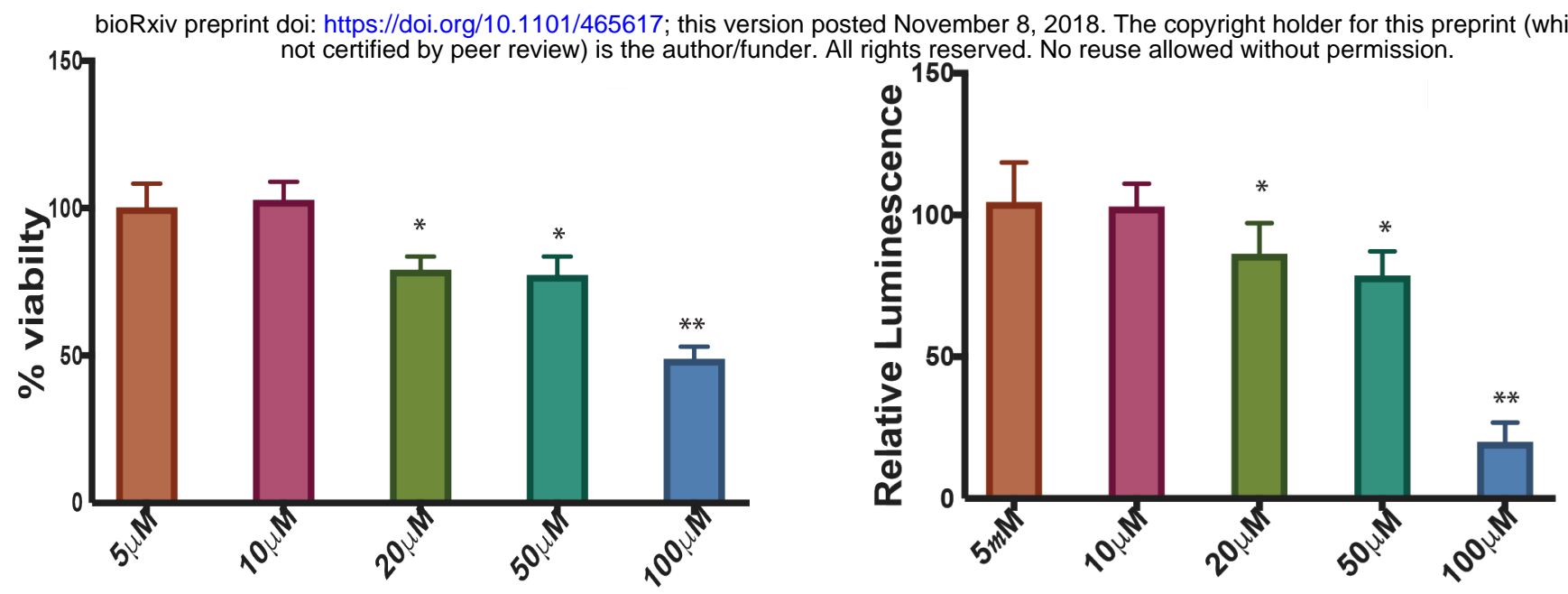

B

CAOV3 cells treated with LY364947

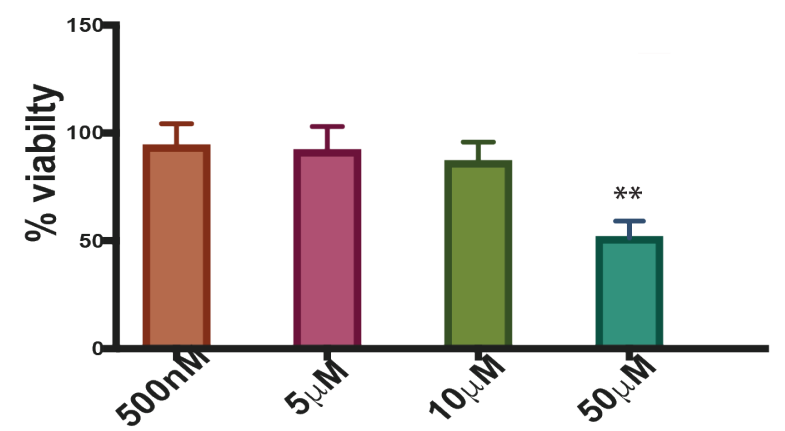

c

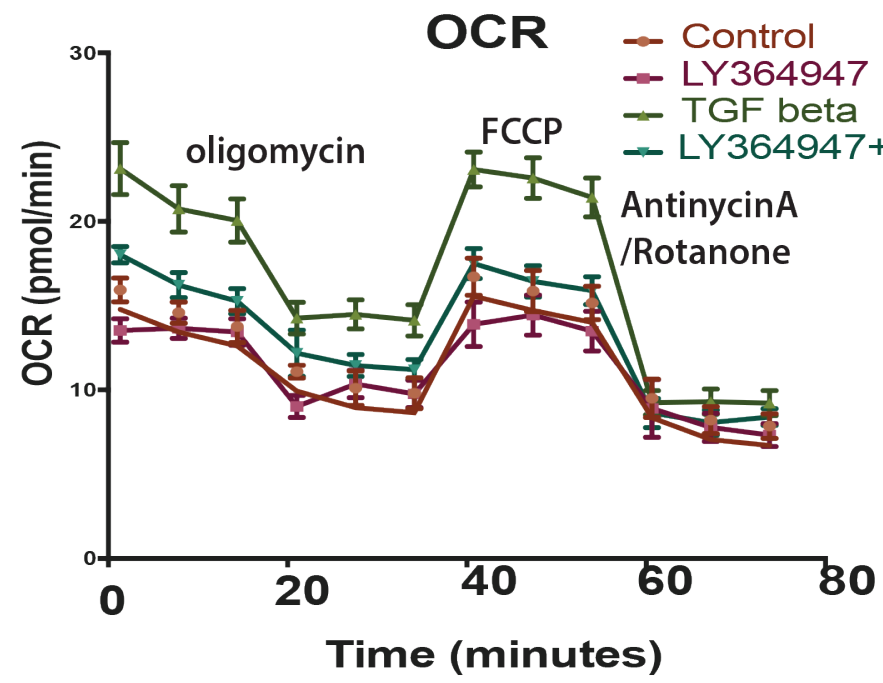

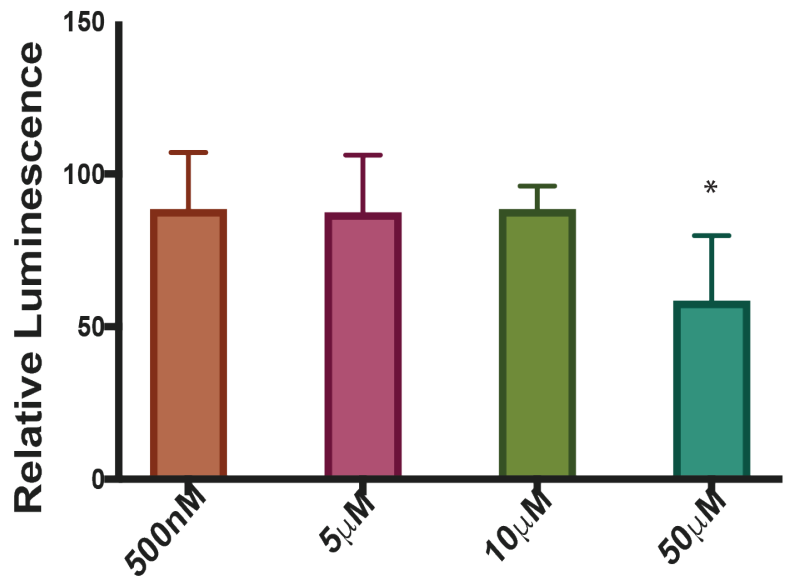

Basal respiration

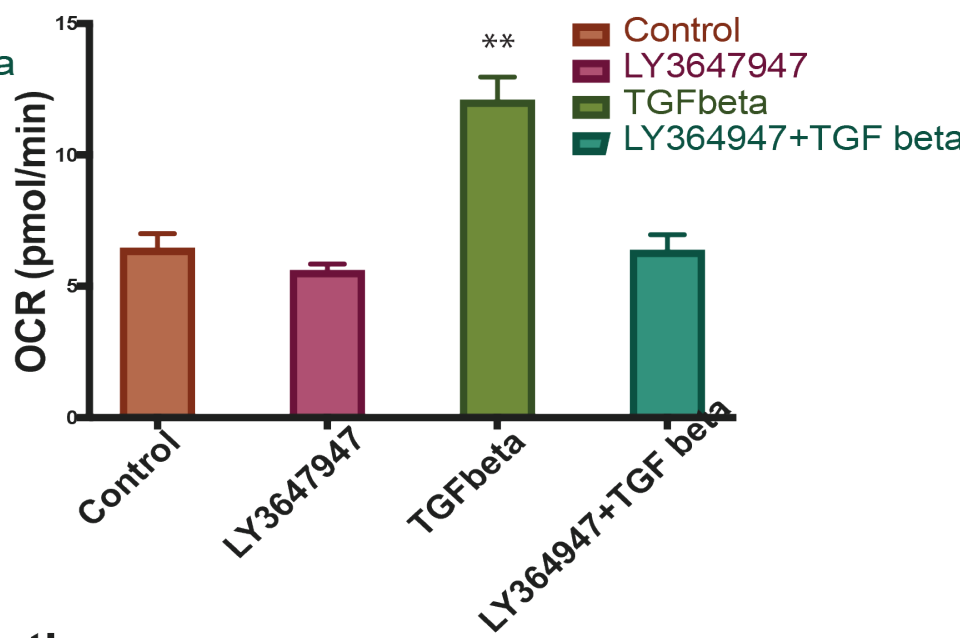

ATP Production

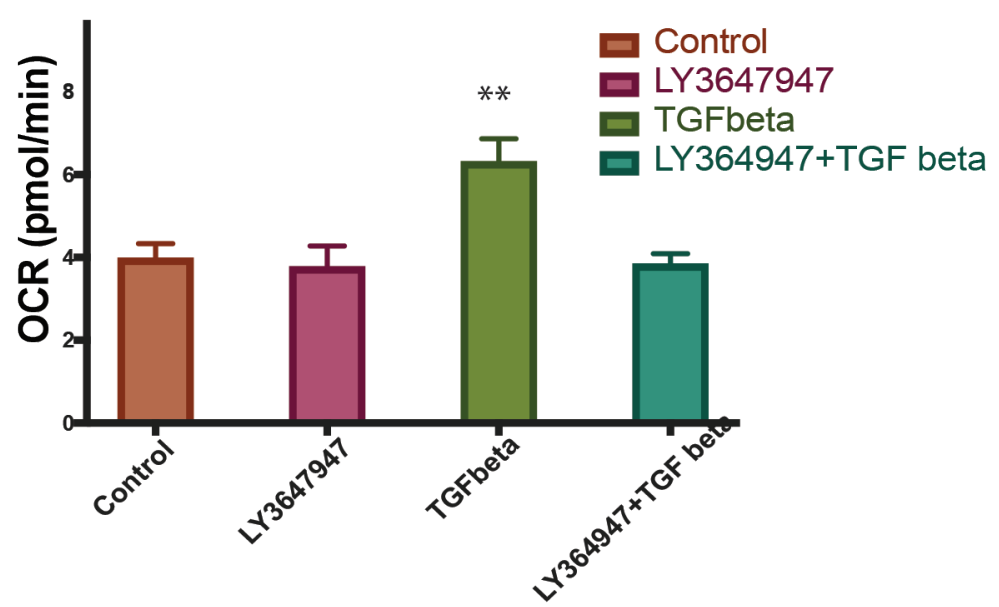




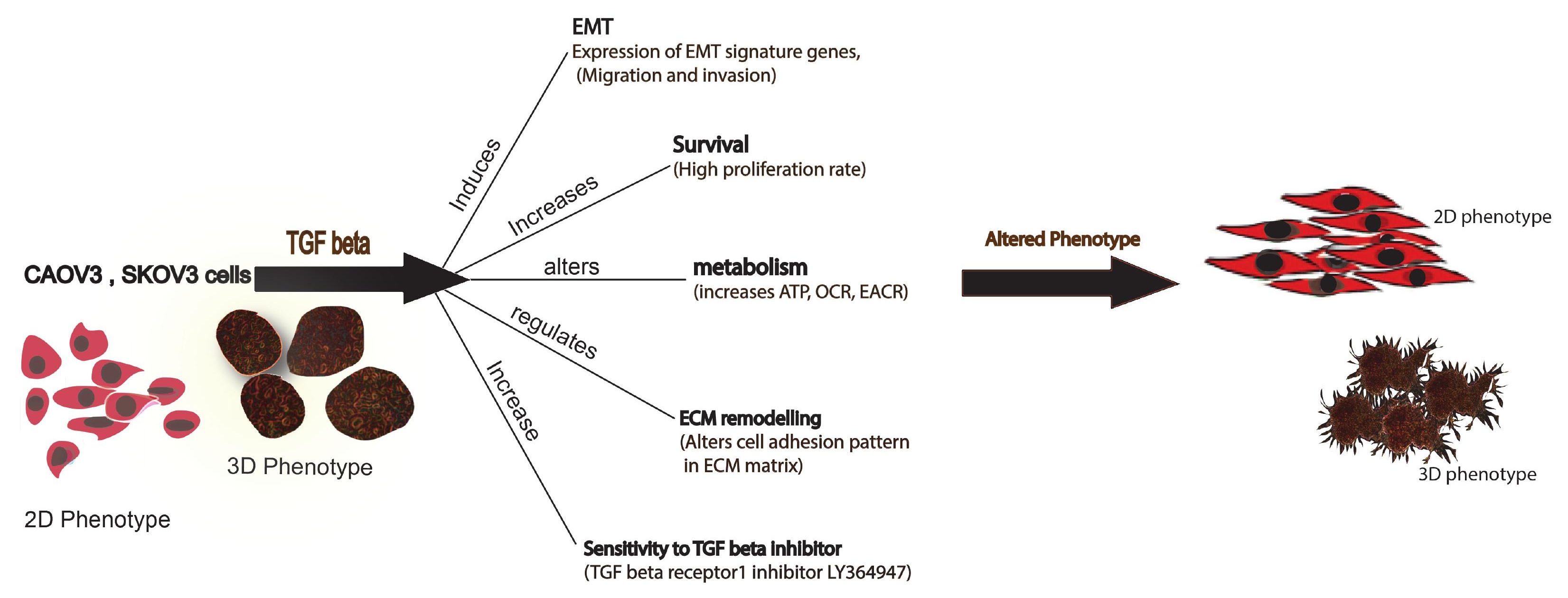


Table 1: Gene expression in ovarian cancer cells $3 \mathrm{~d} v s 2 \mathrm{~d}$

\begin{tabular}{|c|c|c|c|c|c|}
\hline Fold Activation $(\log 2)$ & PA1 & SKOV3 & OVCAR3 & SW626 & CAOV3 \\
\hline EPCAM & 3.738389254 & 0.222628281 & 0.555201232 & 1.634550691 & 0.591436386 \\
\hline OCT & -1.41452539 & 0.331508011 & 2.013752699 & 2.629172087 & 1.986875534 \\
\hline $\mathrm{HIF}$ & 1.288842559 & 0.986022949 & 0.580035508 & 0.826325119 & 0.779427826 \\
\hline MYC & -0.269337326 & 0.871306717 & 1.069765091 & 1.014091492 & 1.443744659 \\
\hline CAV & 2.11570549 & -2.622070313 & 0.775948822 & -0.077529907 & 2.28952527 \\
\hline SNAIL & -0.558730423 & 0.48181662 & 0.867202759 & 2.984481812 & 1.778181076 \\
\hline TWIST & 2.76284337 & -1.226268768 & 0.852192581 & 3.070891619 & 0.818198502 \\
\hline MUC & 0.828931153 & -2.578754425 & 2.153484344 & 2.04488945 & 3.959383726 \\
\hline VIM & 1.274195313 & -1.271252275 & 1.325333238 & 1.738594055 & -3.084840059 \\
\hline CD24 & 0.685231507 & 1.066521287 & 1.630719781 & 1.300624847 & 1.303698182 \\
\hline CD44 & -0.768234253 & 0.111271538 & 0.312582642 & -1.267508864 & 3.468816042 \\
\hline $\mathrm{CDH} 2$ & 0.963071167 & -0.610940933 & 0.548122406 & 0 & 1.029940963 \\
\hline COL1 & 0.360669464 & 2.599440336 & -0.356484741 & 3.807093382 & 2.638355255 \\
\hline COL3 & 2.190701246 & 10.34201813 & 0.343558639 & 0 & 0 \\
\hline COL4 & 0.954000175 & -0.039617538 & 1.224700332 & -0.851626098 & 3.431987047 \\
\hline COL5 & 0.891773224 & 1.911197662 & 0.533273697 & 2.736856461 & 3.117541075 \\
\hline COL6 & 0.938853562 & 3.132226944 & -1.22402513 & 0 & 3.227620363 \\
\hline MMP2 & 1.680223465 & 0.157706574 & 1.369318366 & 2.565864563 & -1.250200868 \\
\hline FN & 3.490255356 & -0.102362312 & -1.775073051 & -0.393338531 & -0.388947159 \\
\hline FOX & 5.905489445 & -0.48019281 & 0.141775444 & -4.870362759 & 1.235244155 \\
\hline CDH1 & -1.868629456 & -0.147729233 & -0.155950859 & -1.10428369 & -1.72478807 \\
\hline ITGA & 4.552867889 & -0.490844727 & 1.779929757 & -2.290222168 & 0.687124908 \\
\hline IMB & 1.085685134 & -0.102712631 & -0.657568276 & -1.366125703 & -0.767904282 \\
\hline TGFBA & 2.177031755 & -0.235479355 & -1.090661645 & -0.086219788 & -0.854101181 \\
\hline TGFBETA2 & 0 & -0.38160643 & 1.812105536 & -3.274260283 & -1.355266571 \\
\hline DESMO & 3.632069826 & -0.241256073 & 2.011571646 & -1.899904251 & 3.80264163 \\
\hline VITRO & -0.198496506 & -0.242904663 & 1.306180596 & -3.250710726 & -1.481752396 \\
\hline
\end{tabular}


bioRxiv preprint doi: https://doi.org/10.1101/465617; this version posted November 8, 2018. The copyright holder for this preprint (which was not certified by peer review) is the author/funder. All rights reserved. No reuse allowed without permission. 